\title{
Dictamen emitido a requerimiento del Ayuntamiento de Santillana del Mar, sobre deslinde de términos entre los municipios de Santillana del Mar, Reocín y Torrelavega
}

\author{
Luis Calvo Sánchez \\ Seminario de Derecho Administrativo \\ Facultad de Derecho de la Universidad de Cantabria
}

\section{ANTECEDENTES}

1. El 8 de julio de 1988 las comisiones municipales de los Ayuntamientos de Santillana del Mar, Torrelavega y Reocín se reunieron con objeto de verificar un deslinde "jurisdiccional». "A la vista de la documentación y planos exhibidos por el personal del Instituto Geográfico Nacional, desde el año 1926 existía un mojón de deslinde entre las jurisdicciones de Torrelavega, Reocín y Santillana del Mar. Según consta en las actas correspondientes, se ha dicho (sin explicar la motivación), que en el año 1951, reunidas las autoridades locales de los citados Ayuntamientos, adoptaron el acuerdo de invalidar el mojón. En consecuencia, desde 1951, existen unos terrenos en el entorno de dicho mojón, con indeterminación de la Jurisdicción Municipal en que quedan incluidos", así reza el acta levantada por el Ingeniero Agrónomo designado por la Consejería de Ganadería, Agricultura y Pesca de la Comunidad Autónoma de Cantabria. El motivo último desencadenante del deslinde es, como también se refleja en dicha acta, que "precisamente sobre estos terrenos se va a ubicar el Hospital de Torrelavega». El acto se cerró sin llegar a acuerdo alguno entre los Ayuntamientos.

2. Algún tiempo más tarde, el 18 de marzo de 1991, e iniciadas ya las obras del hospital comarcal, el municipio de Santillana del Mar tomó la iniciativa para determinar la línea divisoria de su término municipal con los limítrofes de Torrelavega y Reocín, en torno al mojón común a los tres términos. Al efecto, acordó incoar el expediente de deslinde a que hace referencia el art. 18.2 del vigente Reglamento de Población y Demarcación Territorial. De acuerdo con dicho precepto y el art. 10 del Texto Refundido de las disposiciones locales vigentes en materia de régimen local, el ex- 
pediente debía ser resuelto por la Comunidad Autónoma, previo informe del Instituto Geográfico Nacional y dictamen del Consejo de Estado. Por lo que la Diputación Regional de Cantabria envió la documentación aportada por dicho Ayuntamiento al Instituto Geográfico Nacional.

3. El día 3 de julio de 1991, el Instituto Geográfico Nacional convocó a los tres Ayuntamientos en el lugar litigioso, procediéndose a un replanteo del «mojón de los tres términos» común a Torrelavega, Santillana del Mar y Reocín y de los tramos de línea límite contiguos al mismo. El informe que sobre el replanteo elaboró el. Servicio de Deslindes y Grandes Escalas del Instituto Geográfico Nacional, fechado el 15 de octubre de 1991, textualmente dice: «... En la últimas Actas de deslinde vigentes, de fecha 11 de junio de 1951 no hubo acuerdo exclusivamente en este mojón de tres términos, por lo que los tres tramos últimos de la línea límite que concurrieron en él quedaron sin definir. Sin embargo, las Actas de deslinde, de fecha 18 y 19 de junio de 1925, señalaban un mojón común M3T acordado entonces, que las posteriores actas ya citadas vigentes, de fecha 11 de junio de 1941 (quiere decir 1951), anularon. Los cuadernos topográficos de campo de aquellas primeras Actas anuladas contenían los datos precisos suficientes para los replanteos de las tres líneas y con ellos se llegó en campo al encuentro del citado mojón M3T que se conservaba según la descripción de esas Actas, oculto actualmente en el arbolado. Con todos estos datos se ha dibujado el plano que se adjunta (que puede observarse en la página siguiente), a la escala de 1:5000 que se indica, donde se observa que el antiguo mojón M3T acordado en fecha 18 y 19 de junio de 1925 y en desacuerdo posterior, de fecha 11 de junio de 1941 (1951), y por consiguiente sin definir en la actualidad, queda situado de tal forma que las rectas que definen los últimos tramos de las dos líneas límite entre Santillana del Mar y Reocín y entre Torrelavega y Reocín, dividen los edificios del Hospital Comarcal y del INSERSO, quedando el primero de ellos en los Términos Municipales de Santillana del Mar y Reocín y el segundo en los de Santillana del Mar y Torrelavega».

4. La Consejería de Presidencia de la Diputación Regional de Cantabria a la vista del anterior informe, se dirigió al Instituto Geográfico Nacional para solicitarle una aclaración del mismo, toda vez que en él no se hacía referencia específica a las actas levantadas por las Corporaciones Locales afectadas que reflejaran el desacuerdo, así como porque no contenía una concreta propuesta de deslinde.

5. El Instituto Geográfico Nacional, por medio de su Servicio de Deslindes y Grandes Escalas elaboró, entonces, un nuevo informe el 5 de agosto de 1992. 


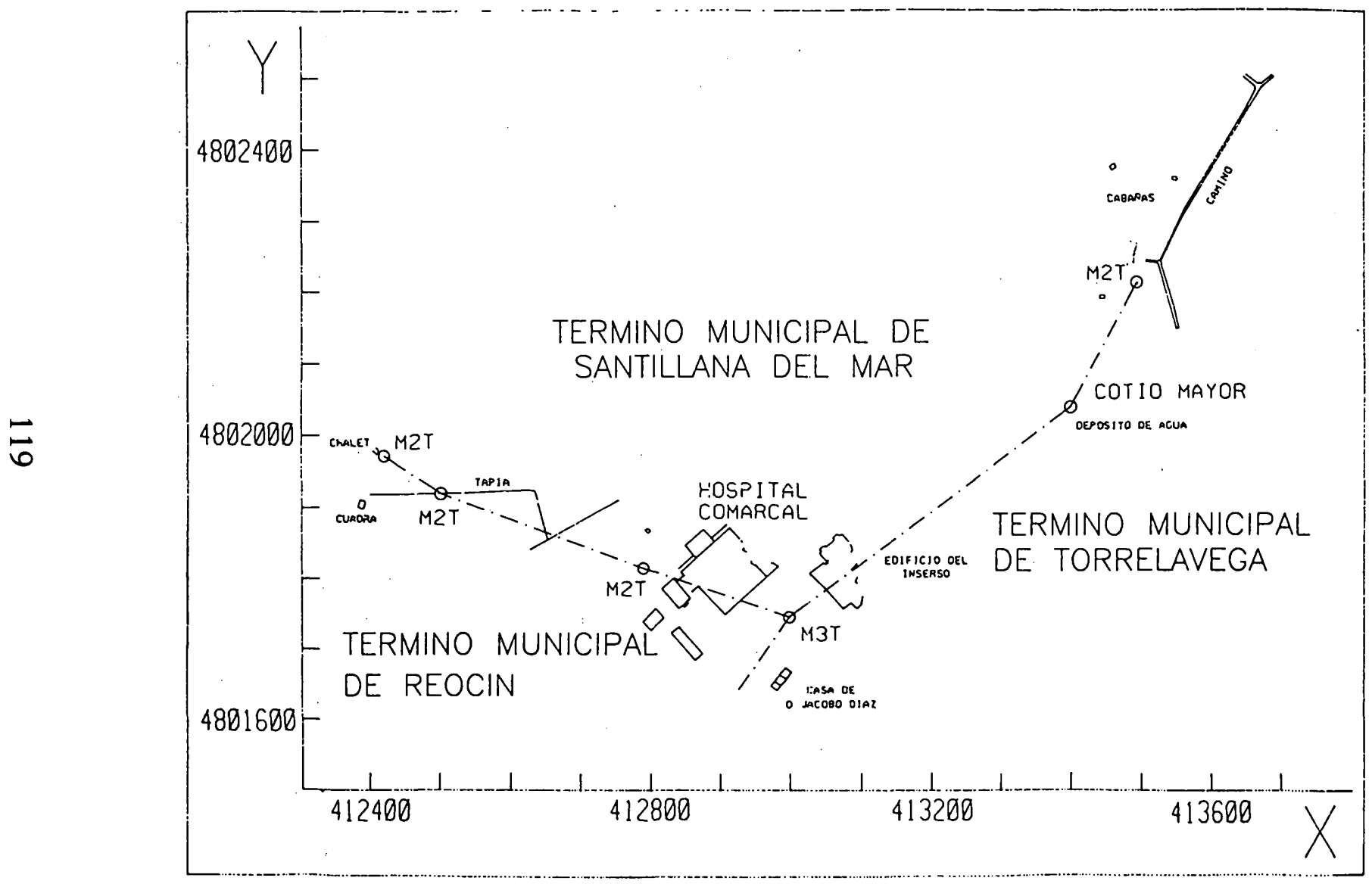


En los antecedentes del informe puede leerse que: «con fecha 18 de marzo de 1991, el Ayuntamiento de Santillana del Mar eleva un escrito a la Diputación Regional de Cantabria, solicitando el deslinde de su término municipal con los limítrofes de Torrelavega y Reocín respecto a la ubicación, en la parcela denominada "Sierrallana», del M3T o mojón común a los tres citados términos, dado que de la exacta posición del citado mojón, depende el hecho de que la propiedad del terreno sobre el que se asienta el Hospital Comarcal de Torrelavega, de reciente construcción, pertenezca a uno u otro término municipal (sic). A este respecto hay que manifestar que en el Acta de Deslinde vigente de fecha 11 de junio de 1951 entre los términos municipales de Santillana del Mar y Torrelavega, en el que de forma expresa mediante Acta adicional de 26 de junio de 1951 se procede a la anulación del Acta de Deslinde anterior entre los citados términos, de fecha 18 de junio de 1925, se establece respecto del controvertido mojón, textualmente lo siguiente:

«Primer mojón. No existiendo conformidad entre las Comisiones de los Ayuntamientos que asisten a esta operación, respecto a la situación de este mojón que debia ser común a los términos municipales de Reocín, en su anejo de Puente San Miguel, de Santillana del Mar, en su anejo de Mijares y de Torrelavega en su anejo de Ganzo, pertenecientes todos a la provincia de Santander, ni en cuanto a la posesión de derecho, ni a la de hecho, se deja sin describir y en su día se fijará por el Instituto Geográfico y Catastral un punto en el terreno a los solos efectos de los cierres planimétricos de los términos municipales que al mismo deben concurrir, sin que el citado punto prejuzgue nada en relación con las reclamaciones que tengan presentadas o traten de presentar los Ayuntamientos interesados".

Luego de describir las citaciones practicadas a los Ayuntamientos así como el estudio en campo de la línea límite, el informe llegaba a las siguientes "conclusiones»: "de la lectura del Acta de Deslinde vigente de fecha 11 de junio de 1951 entre los términos municipales de Santillana del Mar y Torrelavega, se deduce que no existe en la actualidad acuerdo entre los municipios afectados respecto a la ubicación del M3T o mojón común a los ya citados términos municipales con Reocín. No obstante, a juicio de este Servicio de Deslindes y Grandes Escalas y en base a las alegaciones presentadas por el Ayuntamiento de Torrelavega, éste ha procedido inequívocamente al ejercicio de diferentes actos reveladores de jurisdicción o potestad administrativa en la zona de litigio, circunstancia que establece el Tribunal Supremo en sentencia de fecha 10-12-58, para su aplicación a aquellas situaciones administrativas en las que no existe un deslinde anterior". 


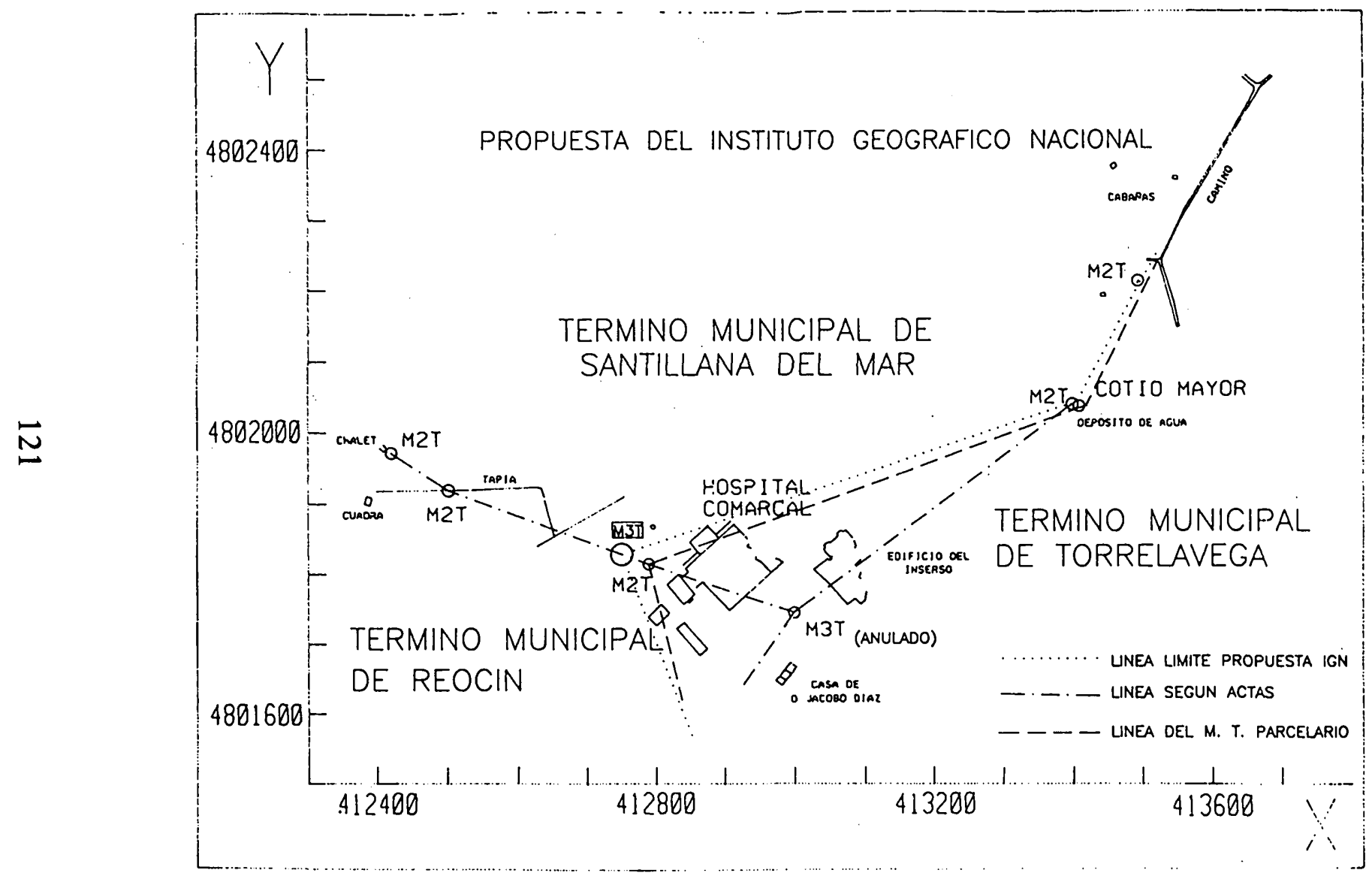


Por lo que el informe concluía con una propuesta de línea límite: «A tenor de lo expuesto con anterioridad, este Servicio de Deslindes y Grandes Escalas propone, según se refleja en el plano a escala 1:5000 que se adjunta (y que puede verse en la página precedente), situar convenientemente el M3T o mojón común a los términos municipales de Torrelavega, Santillana del Mar y Reocín, de manera que la totalidad del Hospital Comarcal de Torrelavega esté situado sobre terreno propiedad del citado Ayuntamiento, es decir, dentro del término municipal de Torrelavega" (sic).

6. La Consejería de Presidencia de la Diputación Regional de Cantabria, el 25 de agosto de 1992, solicitó de nuevo al Instituto Geográfico Nacional aclaración sobre algunos de los extremos de su nuevo informe, concretamente: $1 .^{\circ}$ si el antiguo mojón M3T acordado en 18 de junio de 1925 tiene actualmente alguna validez o ha de considerarse anulado por el acta de deslinde de 11 de junio de $1951 ; 2 .^{\circ}$ la acreditación en el expediente del ejercicio de actos reveladores de jurisdicción y potestades administrativas por el Ayuntamiento de Torrelavega; $3 .^{\circ}$ si se han tomado en consideración las alegaciones vertidas por los otros dos Ayuntamientos en litigio, los de Santillana del Mar y Reocín en la formulación de la propuesta. El escrito se cerraba con un punto $4 .^{\circ}$ en el que la Consejería exponía su opinión acerca de la indiferencia de la ubicación del hospital comarcal a los efectos de la práctica del deslinde.

7. El Jeje de Deslindes y Grandes Escalas del Instituto Geográfico Nacional cursó un escrito, el 6 de octubre de 1992, contestando a las peticiones de aclaración formuladas por la Diputación Regional. 1. ${ }^{\circ}$ En el informe se indicaba claramente que el acta de deslinde vigente de fecha 11 de junio de 1951 anulaba de forma expresa el Acta de 18 de junio de 1925. 2..$^{\circ}$ Las alegaciones formuladas por el Ayuntamiento de Torrelavega se hallaban recogidas documentalmente y a juicio del Servicio eran razonablemente fundadas «sin que ello presuponga dado que tan sólo se emite una propuesta de deslinde, que el Organismo encargado de resolver el expediente, acepte total o parcialmente la respuesta». 3. ${ }^{\circ}$ Las alegaciones presentadas por los Ayuntamientos de Santillana del Mar y Reocín basaban su propuesta en la determinación del M3T a partir de la información contenida en el Acta de deslinde de 18 de junio de 1925, "lo cual no es posible... pues dicha acta fue anulada por el Acta posterior de fecha 11 de junio de 1951 ». Y 4..$^{\circ}$ «Este Servicio ha considerado oportuno a la hora de efectuar la propuesta de deslinde, tener en cuenta la ubicación del Hospital Comarcal de Torrelavega, en evitación de posibles problemas de índole administrativa que pudieran surgir si dicha construcción se hallase emplazada entre dos o más términos municipales» (sic). 
El Servicio de Deslindes y Grandes Escalas del Instituto Geográfico Nacional se ratificó el 12 de enero de 1993 y posteriormente el 1 de septiembre del mismo año en su anterior informe-propuesta y siguientes notas aclaratorias, a petición expresa de la Consejería de la Presidencia de la Diputación Regional de Cantabria.

8. El Gabinete de Administración Local, dependiente de la Consejería de la Presidencia de la Diputación Regional de Cantabria, emitió un informe en relación con el expediente de deslinde de los términos municipales de Reocín, Torrelavega y Santillana del Mar. En el que tras examinar la propuesta formulada por el Instituto Geográfico Nacional, observó que: a) se considera como elemento determinante de deslinde la situación del Hospital Comarcal para con ello evitar problemas administrativos, lo que no es de recibo, pues en un expediente de deslinde resulta indiferente el municipio en que pueda quedar emplazado el hospital comarcal, que no es objeto del mismo, sino el deslinde de los tres términos municipales de referencia...; b) con la indicada propuesta se alteraría además la ubicación del mojón número 2 , efectuada en 11 de junio de 1951, lo que se realizó de común acuerdo entre los tres Ayuntamientos de referencia. Por otra parte, resulta evidente que el deslinde entre los tres municipios ha venido siendo, desde 1951, por lo que concierne a los mojones números 1 y 2 , el señalado con fecha 11 de junio de dicho año, y por lo que respecta al mojón número 3 , el efectuado en el año 1926, aunque haya sido con carácter provisional, y en la situación que se indica por el Instituto Geográfico en su informe de 28 de octubre de 1991.

Por todo ello, el Gabinete de Administración Local propuso que el mojón número 3 , común a los términos municipales de Torrelavega, Santillana del Mar y Reocín se ubicara en el lugar en que fue situado en el deslinde efectuado en 8 de julio de 1926, y los mojones números 1 y 2 , de acuerdo como quedaron señalados en el deslinde practicado en 11 de junio de 1951. Propuesta que fue asumida posteriormente por la Consejería de la Presidencia de la Diputación Regional de Cantabria el 28 de enero de 1993.

9. Remitido el expediente por la Diputación Regional de Cantabria al Consejo de Estado para su dictamen, el mismo lo evacuó con fecha 9 de diciembre de 1993 en el sentido de confirmar los términos propuestos por el Instituto Geográfico Nacional. Sin perjuicio de exponer con más detalle en el cuerpo del dictamen sus fundamentos, a tal conclusión llega siguiendo dos líneas sucesivas de razonamiento. Primera, que el Acta de deslinde de 26 de junio de 1951 suscrita por los tres Ayunta- 
mientos recoge su expresa voluntad de anular en su totalidad el Acta de deslinde levantada el 18 de junio de 1925 en la que se señalaba el M3T. Segunda, a falta de deslindes anteriores consentidos, ha de atenerse a la existencia de actos reveladores del ejercicio de potestades administrativas en la zona controvertida; que, a su juicio, sólo habían sido realizados por el Ayuntamiento de Torrelavega, sin que constara ni siquiera la mención de otros actos de los dos restantes Ayuntamientos en litigio.

10. El Consejo de Gobierno de Cantabria, apartándose del dictamen del Consejo de Estado y de la propuesta del Instituto Geográfico Nacional, aprobó el Decreto 4/1994, de 1 de febrero, disponiendo, según afirma su art. único, la aprobación del deslinde de los términos municipales de Reocín, Santillana del Mar y Torrelavega, en los términos siguientes: "Que el mojón número 3, común a los términos de Reocín, Santillana del Mar y Torrelavega, se ubique en el lugar en que fue situado en el deslinde efectuado el 8 de julio de 1926, y los mojones números 1 y 2, de acuerdo como quedaron señalados en el deslinde practicado en 11 de junio de 1951 ». Es decir, en el sentido indicado en su informe por su Gabinete de Administración Local.

11. El Ayuntamiento de Torrelavega interpuso contra el Decreto citado recurso contencioso-administrativo ante el Tribunal Superior de Justicia de Cantabria. Por sentencia de 30 de mayo de 1995, estimatoria del recurso, se anula el deslinde aprobado por la Diputación Regional de Cantabria, ordenando, en su lugar, que la ubicación del M3T sea la que figura en el informe-propuesta del Instituto Geográfico Nacional. La decisión judicial sigue, en líneas generales, la argumentación del Consejo de Estado, por lo que remito también al cuerpo del Dictamen para el examen de las razones y motivos que han guiado la decisión judicial.

\section{CONSULTA}

Por el Ayuntamiento de Santillana del Mar se me consulta acerca de los siguientes extremos:

1. Sobre la validez y eficacia de los tres deslindes efectuados entre los municipios afectados entre los años 1925 y 1926.

2. $\quad$ Sobre la validez y eficacia de los dos deslindes practicados en el año 1951 y la eventual «anulación» por éstos de los llevados a cabo en 1925 y 1926. 
DICTAMEN EMITIDO A REQUERIMIENTO DEL AYUNTAMIENTO DE SANTHLANA DEL MAR

3. Sobre la utilización de los criterios que han de tomarse en consideración para resolver el expediente de deslinde; en concreto, si ha de estarse a la existencia de anteriores deslindes practicados de conformidad por los municipios.

4..$^{-}$Sobre el empleo en el presente supuesto del criterio subsidiario de la existencia de actos reveladores del ejercicio de potestades administrativas.

\section{DICTAMEN}

I. LA LEGISLACIÓN SOBRE DESLINDES DE TÉRMINOS MUNICIPALES. EXAMEN E INTERPRETACIÓN DE LA NORMATIVA VIGENTE, Y POR TANTO APLICABLE, EN LAS FECHAS EN QUE SE PRACTICARON A LOS DESLINDES DE LOS AÑOS 1925-1926 Y 1951.1. UN PUNTO DE PARTIDA: EL DECRETO, DE 23 DE DICIEMBRE DE 1870, MANDANDO A PROCEDER EN UN BREVE PLAZO AL SEÑALAMIENTO DE LOS TÉRMINOS MUNICIPALES. 2. LAS LEGISLACIONES SECTORIALES. A) La «estadística»: la confección del Mapa Topográfico Nacional. B) La «fiscal»: la normativa sobre la confección del Catastro Parcelario. 3. EL REAL DECRETO, PRESIDENCIA DEL DIRECTORIO MILITAR, DE 2 DE JULIO DE 1924, POR EL QUE SE APRUEBA EL REGLAMENTO SOBRE POBLACIÓN Y TÉRMINOS MUNICIPALES. A) El deslinde de «mutuo acuerdo» o deslinde "practicado de conformidad por los municipios»: el art. 27 del Reglamento de 2 de julio de 1924. B) El deslinde "controvertido": los arts. 28 y 29 del Reglamento de 2 de julio de 1924. C) La perpetuación en el tiempo por las normas reguladoras de los deslindes de términos municipales de la distinción entre el deslinde "de mutuo acuerdo» y el deslinde "controvertido". II. VALIDEZ Y EFICACIA DE LOS DESLINDES PRACTICADOS EN LOS AÑOS 1925-1926. EL RECONOCIMIENTO DE LAS LINEAS DE TERMINOS EXISTENTES EN LOS MUNICIPIOS AL MENOS DESDE EL AÑO 1889. 1. LAS TRES OPERACIONES DE RECONOCIMIENTO DE LA LÍNEA DE TÉRMINO Y SEÑALAMIENTO DE MOJONES COMUNES DE LOS AÑOS 1925 Y 1926. A) Entre Santillana del Mar y Torrelavega, el 18 de junio de 1925. B) Entre Santillana del Mar y Reocín, el 19 de junio de 1925. C) Y entre Torrelavega y Reocín, el 18 de julio de 1926. 2. ALCANCE, NATURALEZA Y CARÁCTER DE LAS OPERACIONES PRACTICADAS EN 1925 Y 1926. A) La persistencia de las líneas de términos existentes entre los municipios al menos desde el año 1889. B) La finalidad estadística y catastral de las operaciones practicadas. C) Su carácter de «mutuo acuerdo» 3. 
LA VALIDEZ DE LOS DESLINDES PRACTICADOS EN 1925-1926. A) Determinación de la normativa que rigió la práctica de los deslindes de 1925-1926. B) Validez y eficacia de los deslindes. III. INVALIDEZ E INEFICACIA DE LAS OPERACIONES DEL AÑO 1951. 1. LAS DOS OPERACIONES DE RECONOCIMIENTO DE LA LINEA DE TÉRMINO Y SEÑALAMIENTO DE MOJONES COMUNES DE 1951. A) Entre Santillana del Mar y Reocín, el 9 de junio de 1951. B) Entre Santillana del Mar y Torrelavega, el 11 de junio de 1951. 2. ALCANCE, NATURALEZA Y CARÁCTER DE LAS OPERACIONES PRACTICADAS EN 1951. A) El carácter "controvertido" del deslinde. La indefinición de las líneas de término como consecuencia del desacuerdo. B) La finalidad estadística y catastral de las operaciones. 3. INVALIDEZ DE LOS DESLINDES DEL AÑO 1951. A) Determinación de la normativa aplicable a los deslindes del año 1951. 1. La vigencia del Reglamento sobre Población y Términos Municipales de 1924. Su aplicación. 2. La normativa catastral. El Decreto-ley de 3 de abril de 1925, sobre formación del Catastro Parcelario Jurídico y el de 30 de mayo de 1928 aprobado para el cumplimiento del anterior. B) Para el Derecho no existen actos, válidos y perfectos de deslinde, en 1951, porque los expedientes nunca llegaron a concluirse. 1. Al resultar "controvertidos» los deslindes era preceptiva una resolución del Ministerio de Gobernación que pusiera fin a los mismos; lo que nunca se produjo. 2. Las operaciones de 1951 son meros actos de trámite de un procedimiento inconcluso que, en consecuencia, no pudieron sustituir a los deslindes existentes. C) Sobre el contenido: la indefinición resultante de los actos de trámite de los expedientes de deslindes de 1951. D) Sobre la "anulación» de las Actas de deslinde, de 18 y 19 de junio de 1925, llevadas a cabo por las Actas adicionales a las anteriores, de 26 de junio de 1951 y de 21 de julio de 1945. 1. Las Actas adicionales de 26 de junio de 1951 (complementaria de la de 18 de junio de 1925) y 21 de julio de 1951 (complementaria de la de 19 de junio de 1925). 2. Para el Consejo de Estado y el Tribunal Superior de Justicia de Cantabria, el coincidente parecer de las tres representaciones municipales en su voluntad de anular las actas de deslinde de 1925 hace decaer la posibilidad de su utilización para la fijación del M3T. 3. El pretendido alcance "anulatorio" de las Actas adicionales. A) Su significado y valor jurídico. B) No se puede "anular» un acto administrativo mediante su sustitución por otro acto administrativo. 4. Sobre la conformidad entre los tres Ayuntamientos que participaron en los deslindes de 1951: no hubo "coincidencia» en la voluntad expresa y anulatoria de los tres Ayuntamientos. IV. LA ADMINISTRACION AL RESOLVER EXPEDIENTES DE DESLINDES HA DE BASARSE EN PRIMER LUGAR EN LO QUE RESULTE DE «DESLINDES ANTERIORES PRACTICADOS DE CONFORMIDAD POR LOS MUNICIPIOS». 1. LA DOCTRINA DEL TS SOBRE LA 
PREVALENCIA DE LOS DESLINDES CONSENTTDOS O «DE MUTUO ACUERDO». 2. Y SU APLICACIÓN AL PRESENTE SUPUESTO. $V L A$ EXISTENCIA DE ACTOS REVELADORES DEL EJERCICIO DE POTESTADES ADMINISTRATIVAS COMO CRITERIO SUBSIDIARIO A UTILIZAR PARA RESOLVER LOS EXPEDIENTES DE DESLINDES. 1. LA FORMULACIÓN DEL CRITERIO: EL EJERCICIO DE POTESTADES ADMINISTRATIVAS. SU UTILIZACION SUBSIDIARIA. 2. LOS ACTOS DE DISPOSICIÓN SOBRE BIENES NO SON ACTOS REVELADORES DE POTESTADES ADMINISTRATIVAS. 3. LA EXISTENCIA DE ACTOS REVELADORES DEL EJERCICIO DE POTESTADES ADMINISTRATIVAS POR LOS TRES AYUNTAMIENTOS EN LITIGIO. 4. AL CONTRARRESTARSE LOS ACTOS REVELADORES, EL CRITERIO NO ES APTO PARA SU UTILIZACIÓN.

\section{LA LEGISLACIÓN SOBRE DESLINDES DE TÉRMINOS MU- NICIPALES. EXAMEN E INTERPRETACIÓN DE LA NORMA- TIVA VIGENTE, Y POR TANTO APLICABLE, EN LAS FECHAS EN QUE SE PRACTICARON A LOS DESLINDES DE LOS AÑOS 1925-1926 Y 1951}

1. Un punto de partida: el Decreto, de 23 de diciembre de 1870 , mandando a proceder en un breve plazo al señalamiento de los términos municipales

«Si en todas épocas fue conveniente y necesario determinar con exactitud y claridad el territorio a que cada Ayuntamiento extiende su acción administrativa, mayor motivo y más apremiantes razones lo exigen ahora que la autonomía del Municipio figura en primer término entre las bases de nuestro sistema político. A las corporaciones municipales corresponde hoy en exclusiva competencia la gestión de los intereses de los pueblos: importa, pues, que de un modo permanente se determine y establezca el radio en que las Municipalidades han de ejercer su poderosa y libre influencia, desenvolviendo las amplias facultades de que ahora gozan. La Administración económica, tanto local como general, reclama también con premura esta medida, y la estadística viene a revestirla de más urgente carácter por la necesidad de reunir en breve plazo datos importantes que no pueden conseguirse, dada la confusión en que hoy se hallan los términos municipales, causa permanente de choques, perturbaciones y conflictos entre pueblos comarcanos». Así reza el Preámbulo del Decreto, de 23 de diciembre de 1870, mandando a proceder en un breve plazo al señalamiento de los términos municipales. 
Sucede, en efecto, que estas tres finalidades, la delimitación del espacio físico para el ejercicio de las potestades administrativas municipales (local o «jurisdiccional»), la confección y publicación de un Mapa Topográfico Nacional (estadística), y la formación de un catastro (fiscal) animaron a las autoridades de finales del XIX y principio del XX a emprender una vasta operación de delimitación de los términos municipales españoles.

El citado Decreto, de 23 de diciembre de 1870, sentó las bases genera: les del procedimiento de deslinde de los términos municipales. Su práctica debía intentarse por medio del acuerdo de los municipios limítrofes que, al efecto, debían nombrar sendas comisiones integradas por el $\mathrm{Al}$ calde, tras concejales, el Secretario y un perito ad hoc (art. 2) que debían verificar las operaciones, atendiendo "sólo a la posesión de hecho en el momento de la operación", "sin perjuicio de variar el amojonamiento, previas las oportunas formalidades, cuando se resuelvan las cuestiones que pueda haber pendientes». (art. 3). Unas Instrucciones para llevar a cabo el señalamiento, contenidas en el cuerpo del Decreto de 1870, prescribían la necesidad de levantar acta detallada, firmada por todos los asistentes al acto, que contuviera los antecedentes que hubieran servido para fijar la línea común, describiendo la situación, forma y dimensiones de cada uno de los mojones colocados (art. 6); y cuyo original había de remitirse al Gobierno de la provincia a los sólos efectos de su conservación, quedando en cada Ayuntamiento una copia autorizada (art. 7).

Estas previsiones serán reproducidas sectorialmente por las sucesivas normas que ordenen practicar deslindes de términos municipales, desde la perspectiva de cada una de las finalidades que persigan.

\section{Las legislaciones sectoriales}

\section{A) La "estadística»: La confección del Mapa Topográfico Nacional}

Ya un Decreto de la Regencia de 30 de septiembre de 1870 ordenó la confección y publicación de un Mapa Topográfico Nacional, al que siguió un Real Decreto de 30 de agosto de 1889, ordenando la renovación de los hitos o mojones permanentes que determinen las líneas divisorias de los respectivos términos municipales, excepto en las provincias donde estén terminados por el Instituto geográfico y estadístico los trabajos del mapa. 
Como señalara su Preámbulo, se hallaba sometido a las Cortes un proyecto de ley sobre formación de planos perimetrales de los distritos municipales y «como para practicar las operaciones que en el mismo se ordenan es indispensable como trabajo previo determinar las líneas divisorias de un término municipal con otro, con objeto de que las comisiones de trabajo no necesiten invertir en esta operación preliminar, que pueden efectuar por sí mismo los Ayuntamientos, un tiempo utilizable para la formación y medición de los planos perimetrales", se consideraba preciso adelantar la operación de señalamiento de límites, "que en todo caso siempre llenaría una necesidad pública frecuentemente sentida».

Así pues, es una finalidad estadística, la confección del Mapa, la que persigue la "renovación» de las líneas divisorias de los términos municipales de todas las provincias españolas, «a salvo aquellas en que estuvieran terminados los trabajos del Mapa" (las de Albacete, Cádiz, Córdoba, Jaén, Madrid, Málaga y Sevilla, según su primer artículo).

El procedimiento para la delimitación de los términos seguía en sus líneas generales al establecido en el Decreto de 1870. El deslinde debía intentarse de mutuo acuerdo entre las comisiones municipales (art. 7), de composición idéntica, debiendo guiarse su práctica por los mismos criterios (atendiendo a la posesión de hecho...; art.2), y reflejando también en un acta todas las operaciones practicadas (art. 9). A resultas del mismo, podía haber conformidad o disconformidad de los Ayuntamientos sobre la situación de los mojones. Si lo primero, entonces "unos mismos mojones servirían para los dos términos». Si, lo segundo, cada una de las comisiones debía establecer o reestablecer los que creyera corresponder a la línea que su respectivo Ayuntamiento mantuviera, «sin perjuicio de que en su día, y por los trámites legales y autoridades competentes, se dirima la discordia y se determine la línea que en Derecho corresponda" (art. 11). Se perfilaba así una norma que se generalizará posteriormente: el deslinde puede ser de mutuo acuerdo, en cuyo caso, el mismo es el resultado de un encuentro de voluntades de los Ayuntamientos limítrofes; o controvertido, supuesto en que un "tercero superior», "la autoridad competente» debía resolver la contienda.

\section{B) La «fiscal»: La normativa sobre la confección del Catastro Parcelario}

La Ley de 27 de marzo de 1900, estableciendo el Registro fiscal en todas las provincias, excepto las Vascongadas y Navarra, y dictando dispo- 
siciones sobre catastro por masas de cultivo y clases de terrenos, y cartillas evaluatorias de la riqueza rústica y pecuaria, y derogando la ley de 24 de agosto de 1895, es la primera norma que específicamente ordena, desde este sector, proceder a la delimitación de los términos municipales. Su finalidad era estrictamente fiscal: la creación de un Catastro parcelario, un instrumento indispensable para la implantación de la Contribución Territorial. Y por lo que atañe al procedimiento, su art. 3 ordenaba la delimitación y amojonamiento de las líneas límites de los términos municipales, apoyándose de nuevo, bien que de manera incompleta, en las normas contenidas en el Decreto de 1870: reiteraba la necesidad de trazar una línea de "posesión de hecho" cuando hubiera desavenencias entre los Ayuntamientos, afirmando su provisionalidad hasta que se resolvieran los litigios o reclamaciones que tuvieras pendientes los Ayuntamientos interesados, haciéndose entonces el amojonamiento definitivo; sin que la misma perjudicare o prejuzgare los derechos que pudieran corresponder a cada Ayuntamiento.

Años más tarde, la Ley de 23 de marzo de 1906, que establece el Catastro Parcelario, reproduce su contenido, reiterando a todos los Ayuntamientos la orden de deslindar sus términos municipales, en el improrrogable plazo de un año. Para la colocación provisional de los hitos o mojones de debía atender solamente a la posesión de hecho en el momento en que se llevare a cabo la operación, "conforme a lo prevenido en las disposiciones vigentes" decía su art. 7, en clara remisión al Decreto de 23 de septiembre de 1870, cuyas normas debían seguirse para proceder al señalamiento de los términos municipales: comisiones competentes para la práctica del deslinde, práctica de las operaciones, levantamiento de actas...

\section{El Real Decreto, Presidencia del Directorio Militar, de $\mathbf{2}$ de ju- lio de 1924, por el que se aprueba el Reglamento sobre Pobla- ción y Términos Municipales}

Tanto desde la normativa sobre el Mapa Topográfico Nacional como la catastral, se había venido ordenando la práctica de los deslindes de los términos municipales, apoyándose en el Decreto de 23 de diciembre de 1870 , la norma que ordenaba con carácter general el señalamiento de términos municipales, fuera cual fuese la finalidad que se persiguiera (administrativa, fiscal o estadística). Este papel de cimentación de un régimen jurídico básico y catalizador de la práctica de las operaciones de deslindes fue asumido posteriormente por 
el Real Decreto, de 2 de julio de 1924, por el que se aprueba el Reglamento sobre Población y Términos Municipales. Una norma que contenía tres preceptos, sus artículos 27 a 29 , relativos a la "demarcación, deslinde y amojonamiento" de los términos municipales, que se completaba con la remisión al Decreto de 1870 que realizaba el primero de los citados preceptos ( El deslinde se efectuará con arreglo a los artículos $1 .^{\circ}$ al $7 .^{\circ}$ de las Instrucciones para llevar a cabo el señalamiento de los términos municipales de 23 de diciembre de $1870 »)$.

$\mathrm{Al}$ efecto, articulaba un procedimiento en dos fases, a las que aludían respectivamente el art. 27, por una parte y los arts. 28 y 29 , por otra.

A) El deslinde de "mutuo acuerdo" o deslinde "practicado de conformidad por los municipios»: el art. 27 del Reglamento de 2 de julio de 1924

Según el art. 27 del Reglamento de Población y Términos Municipales de 2 de julio de 1924, "para la demarcación, deslinde y amojonamiento en los términos municipales, los Ayuntamientos a quienes afecte la línea divisoria nombrarán una Comisión, compuesta del Alcalde y de tres Concejales por cada Ayuntamiento, que con el Secretario y el perito que designe la municipalidad verifiquen la operación de deslinde. Unicamente se permitirá la asistencia al acto de la demarcación y deslinde, de dos personas por cada Municipio, que por su edad avanzada puedan justificar el sitio en que estuvieron los mojones o señales divisorias; los propietarios de los terrenos que haya de atravesar el deslinde y la fuerza de la Guardia Civil encargada de mantener el orden». Hasta aquí, el Reglamento de 1924 no era sino reiteración de la norma sentada en el art. 2 del Decreto de 23 de diciembre de 1870, reproducida por la legislación sectorial: las operaciones de deslinde se concebian fundamentalmente como el resultado de un acuerdo de voluntades de los municipios implicados, que intentaba alcanzarse mediante la constitución de sendas comisiones municipales. De ahí que siempre debía intentarse su práctica en primer lugar de mutuo acuerdo. Si existía conformidad entre los Ayuntamientos, ahí concluía el procedimiento, acometiéndose a continuación al amojonamiento, siguiendo las instrucciones para llevar a cabo el señalamiento de los términos municipales contenidas en el Decreto de 1870 . Sólo si no era posible el acuerdo en la fijación de los términos municipales en disputa, resultando controvertido el deslinde, entonces se pasaba a una segunda fase... 
B) El deslinde «controvertido»: los arts. 28 y 29 del Reglamento de 2 de julio de 1924

"Cuando existan divergencias entre los Ayuntamientos respectivos en cuanto a la manera de apreciar el sitio por donde debe pasar la línea divisoria o donde deban colocarse los hitos o mojones", indicaba el art. 28 del Reglamento de 1924, "cada Comisión levantará acta por separado, en la que harán constar todos los datos, antecedentes y detalles que juzgue necesarios para justificar su apreciación, y se dará con esto por terminado el acto".

Constatadas las divergencias entre los Ayuntamientos, el procedimiento no fenecía ahí, sino que se abría una segunda fase, que sólo era procedente precisamente en estos supuestos en los que el deslinde había devenido "controvertido"; y que describía el art. 29, la última de las normas relativas al deslinde:

"Las Alcaldías respectivas remitirán las actas, con los demás antecedentes, al Gobernador Civil, que enviará el expediente a la Dirección general del Instituto Geográfico, para que designe el Ingeniero o Ingenieros que hayan de constituirse sobre el terreno: a fin de determinar, en vista y de conformidad con los documentos indicados, el deslinde de los términos municipales correspondientes. El Ministerio de la Gobernación resolverá el expediente, previo informe del Instituto. Contra su resolución podrá interponerse recurso contencioso-administrativo".

Justamente por su carácter "controvertido", se hacía necesaria la decisión de la contienda por un tercero «superior», el Ministerio de la Gobernación, cuya resolución ponía fin al expediente de deslinde, fijando indubitadamente las líneas del término municipal discutidas; previa una intervención técnica encomendada a un órgano de prestigio reconocido, el Instituto Geográfico. Contra la decisión ministerial sólo se abría ya la vía judicial.

En conclusión, existía una diferencia procedimental, perfectamente justificada por lo demás, entre los deslindes "de mutuo acuerdo" o "practicados de conformidad" por los municipios, prevista en el art. 27 del Reglamento de 1924, y los deslindes "controvertidos", en los arts. 28 y 29 del mismo. En el primer caso, el acto de deslinde quedaba perfeccionado por el acuerdo de voluntades de los Ayuntamientos afectados, sin injerencia externa, no había intervención administrativa alguna de la "superioridad", cuya participación quedaba reducida a la conservación de las actas del deslinde (art. 7 de las Instrucciones contenidas 
en el Decreto de 1870), pero sin que ostentara facultad decisoria alguna. En el segundo, en cambio, el acto de deslinde, era un acto del Ministerio de la Gobernación que, como tercero "superior», resolvía el expediente luego de existir disconformidad entre los Ayuntamientos afectados...

C) La perpetuación en el tiempo por las normas reguladoras de los deslindes de términos municipales de la distinción entre el deslinde "de mutuo acuerdo" y el deslinde "controvertido"

Esta dicotomía procedimental, deslinde "de mutuo acuerdo" y deslinde "controvertido" traducida en una diferente competencia para la resolución de los expedientes de deslinde, que instaurara el Reglamento de 1924 se ha perpetuado en el tiempo a través de las normas que sucesivamente han regulado el deslinde de los términos municipales. El tenor del art. 17 de la Ley municipal de 31 de octubre de 1935 era harto elocuente: «los términos municipales podrán ser rectificados y deslindados en virtud de acuerdos de las Corporaciones interesadas, y cuando no hubiere conformidad entre ellas por resolución del Gobierno previo expediente e informe del Consejo de Estado». E igual sucedió con las Leyes franquistas de régimen local, aunque sólo se fijaran en los deslindes "controvertidos" para atribuir la competencia de su resolución al Ministerio de la Gobernación; así, por todas, el art. 21 del Texto Articulado de la Ley de Administración Local, aprobado por Decreto de 14 de diciembre de 1950: "las cuestiones que se susciten entre Municipios sobre el deslinde de sus términos municipales serán resueltas por el Ministerio de la Gobernación, previo informe del Instituto Geográfico y Catastral y dictamen del Consejo de Estado" (del mismo tenor, el art. 21 del Texto Articulado y Refundido, de Régimen Local, de 24 de junio de 1955).

También los dos Reglamentos de Población y Demarcación Territorial posteriores al de la dictadura de Primo de Rivera consagran esta distinción: el que lo sustituyó, el Decreto 17 de mayo de 1952 y el vigente, que a su vez derogó al anterior. El art. 30 del primero de los $\mathrm{Re}$ glamentos, aludiendo al deslinde "de mutuo acuerdo" afirma literalmente que «si hubiera conformidad en la fijación de líneas límites, las Comisiones designadas por los Ayuntamientos levantarán acta conjunta que lo acredite, procederán de común acuerdo a la colocación de los hitos o mojones que señalen los límites y remitirán copias de dichas actas al Ministerio de la Gobernación y al Instituto Geográfico y Catastral». En tanto que al "controvertido" se refieren los arts. 27 y 32 
también del Decreto de 1952. El primero, ordenando levantar actas por separado a cada comisión "cuando existan divergencias entre los Ayuntamientos respectivos», debiendo remitirse las mismas al Gobernador Civil, quien enviará el expediente al Instituto Geográfico y Catastral, para que designe el Ingeniero o Ingenieros que deban personarse sobre el terreno, a fin de llevar a cabo en unión de las comisiones el deslinde de los términos municipales. Y el segundo, con la fórmula ya estereotipada según la cual «las cuestiones que se susciten entre Municipios sobre deslinde de sus términos municipales serán resueltas por el Ministerio de la Gobernación, previo informe del Instituto Geográfico y Catastral».

El RD 1690/1986, de 11 de julio, que aprueba el vigente Reglamento de Población y Demarcación Territorial de las Entidades Locales, recoge exactamente las mismas soluciones, con la lógica sustitución de la intervención del Ministerio de la Gobernación (y del Gobernador Civil) por la de la Comunidad Autónoma: en sus arts. 18 y 21 (deslinde "controvertido") y 24 (deslinde "de mutuo acuerdo»). Por lo demás, el Consejo de Estado en su consideración II, confirma este aserto, respecto del vigente procedimiento de deslinde, como a continuación se transcribe: «El deslinde puede resultar de la convergencia entre los Ayuntamientos en cuanto a la manera de apreciar el sitio por donde deba pasar la línea divisoria o en el que hayan de colocarse los hitos o mojones, esto es, de un procedimiento propiamente convencional, resultado de la coincidencia de las comisiones de cada uno de los Ayuntamientos afectados por la demarcación, deslinde y amojonamiento. Pero la operación por la cual se determinan los límites materiales del territorio municipal, su deslinde, puede conducir a una divergencia irreductible por la vía del acuerdo entre los Ayuntamientos afectados...»

\section{VALIDEZ Y EFICACIA DE LOS DESLINDES PRACTICADOS EN LOS AÑOS 1925-1926. EL RECONOCIMIENTO DE LAS LI- NEAS DE TÉRMINOS EXISTENTES EN LOS MUNICIPIOS AL MENOS DESDE EL AÑO 1889}

1. Las tres operaciones de reconocimiento de la línea de término y señalamiento de mojones comunes de los años 1925 y 1926

Entre los años 1925 y 1926 se verificaron tres diferentes operaciones para «reconocer la línea de término y señalar los mojones comunes» de los municipios de Santillana del Mar, Torrelavega y Reocín. 
DICTAMEN EMITIDO A REQUERIMIENTO DEL AYUNTAMIENTO DE SANTILLANA DEL MAR

- La primera de ellas, de la que dan cuenta las Actas de 18 de junio de 1925, reconoció la línea de término entre los municipios de Santillana del Mar y Torrelavega.

- Un día después, el 19 de junio de 1925, se hizo lo propio entre Santillana del Mar y Reocín.

- Y la tercera, la que fijó la línea de término entre Torrelavega y Reocín, no tuvo lugar sino el año siguiente, llevándose a efecto el 8 de julio de 1926.

Una líneas de término ya existentes en los años 1925 y 1926, que fueron objeto de un "reconocimiento", como se comprobará por la lectura de las actas. Destacando ahora que en las operaciones, practicadas «a tres bandas", hubo consenso entre los tres Ayuntamientos, pues aceptaron los mojones, entre ellos el M3T común a los tres municipios, y consiguientemente las tres líneas de término: Santillana del Mar-Torrelavega, Santillana del Mar-Reocín y Torrelavega-Reocín. Pero veamos el contenido de las actas que transcribieron las operaciones de reconocimiento llevadas a efecto.

\section{A) Entre Santillana del Mar y Torrelavega, el 18 de junio de 1925}

Así dice literalmente el Acta de la operación practicada para reconocer la línea de término y señalar los mojones comunes a los términos de Santillana y Torrelavega, de 18 de junio de 1925: "Reunidos el día dieciocho de junio de mil novecientos veinticinco... los señores que con sus respectivos cargos y representación abajo se expresan, previa citación hecha por el Ingeniero... Jefe de la cuarta brigada topográfica, en cumplimiento de lo dispuesto por la ley para la publicación del Mapa de treinta de septiembre de mil ochocientos setenta y la de veintitrés de marzo de mil novecientos seis, sobre formación del Catastro parcelario de España, se procedió a la operación en la forma siguiente...:

$12^{\mathrm{a}}$ Mojón. Se reconoció como tal, una piedra sin labrar, de forma prismática, cuyas dimensiones visibles son: treinta y dos por veintitrés centímetros de base y quince de altura. Está enclavada en el sitio llamado "Sierra de la Gallina», en terreno prado de propiedad de D. Jacobo Díaz, vecino de Torrelavega y a unos sesenta metros al E. de la casa de la finca. Este mojón tiene una P. grabada en la cara O., y es común a los términos municipales de Santillana, en su anejo 
Mijares; Reocín en su anejo Puente San Miguel y Torrelavega en su anejo Ganzo. Desde él no se ve el mojón anterior, divisándose al N. el vértice geodésico de tercer orden «Vispieres» y al E. el topográfico "Cotío Mayor». La línea de términos reconocida entre este mojón y el anterior es la alineación que pasa por ambos».

El mojón reconocido por Santillana del Mar y Torrelavega en este primera operación era el M3T, el común a los municipios de Santillana del Mar, Torrelavega y Reocín: el n. ${ }^{\circ} 12$, último, de la línea de término entre los dos primeros.

\section{B) Entre Santillana del Mar y Reocín, el 19 de junio de 1925}

En los mismos términos literales aparece descrita la operación de reconocimiento de líneas de término practicadas al día siguiente entre Santillana del Mar y Reocín, recogida en las Actas de 19 de junio de 1925, siendo también indubitada la línea de término de estos municipios, aceptándose igualmente el mismo mojón, el M3T, reconocido el día anterior, y que aquí figuraba como mojón $n .^{\circ}$.

\section{C) Y entre Torrelavega y Reocín, el 18 de julio de 1926}

Un año más tarde, el Acta de la operación practicada para reconocer la línea de término y señalar los mojones comunes a los términos municipales de Torrelavega y de Reocín, de 8 de julio de 1926, también recoge la aceptación por estos dos municipios del M3T como mojón n ${ }^{\circ}{ }^{\circ}$, de su línea divisoria:

Primer Mojón. Se reconoció como tal, una piedra sin labrar, de forma prismática, cuya dimensiones visibles son... Este mojón tiene grabada una $\mathrm{P}$. en la cara $\mathrm{O}$. y es común a los términos municipales de Santillana y Torrelavega en su anejo Ganzo. Y este mojón es el mismo que fue reconocido también como común a los tres referidos términos municipales por los Ayuntamientos interesados al verificarse por el Instituto Geográfico el reconocimiento de la línea de término y señalamiento de los mojones comunes a los términos municipales de Santillana y de Torrelavega, según acta firmada en la "Sierra de la Gallina" el día dieciocho de junio de mil novecientos veinticinco, por cuya razón no se ha citado al Ayuntamiento del expresado mojón". 
DICTAMEN EMITLO A REQUERIMIENTO DEL AYUNTAMIENTO DE SANTILLANA DEL MAR

\section{Alcance, naturaleza y carácter de las operaciones practicadas en 1925 y 1926}

A) La persistencia de las líneas de términos existentes entre los municipios al menos desde el año 1889

Según se comprueba por la transcripción de las actas, en 1925 y en 1926 no se practican nuevos deslindes que alterasen los existentes, sino que respetaron los mojones (entre ellos el M3T) y las líneas de término preestablecidas desde antiguo, que venían asi a ser "reconocidas». Líneas y mojones, existentes al menos desde el año 1889, pues en dicho año, se practicaron sendos deslindes entre los tres municipios.

- En efecto, como consta en la primera hoja del expediente de Amojonamiento del año 1889 (Acta de visita a los deslindes y amojonamientos anteriores entre Santillana y Torrelavega, de 20 de septiembre de 1889), el mojón común a los tres términos municipales era pacíficamente admitido en esa fecha, y formaba parte de la línea de término común a los dos municipios. Así se deduce de la lectura del Acta:

«En la sierra de la Gallina, a las nueve de la mañana del día veinte y ocho de septiembre de mil ochocientos ochenta y nueve,... ambas Comisiones municipales, después de acreditar recíprocamente el poder que los mencionados Ayuntamientos les habían conferido para revisar los deslindes y amojonamientos anteriores procedieron a recorrer el primer hito, enclavado en la sierra mencionada, el cual separa también la jurisdicción de Reocín al Oeste...»

Y es que este primer hito de 1889 , común a los tres términos municipales, era exactamente el mismo que el mojón último . $^{\circ} 12$ del reconocimiento de 1925, sólo que invirtiendo la dirección de las líneas, ahora reconocidas de $\mathrm{O}$. a $\mathrm{E}$.

- Y lo propio sucedió en el Acta de deslinde y amojonamiento entre Santillana y Reocín, de 30 de septiembre de 1889, en el que claramente se reconocía el M3T, como el primero de los mojones del deslinde de 1889, luego también reconocido en 1925 entre ambos municipios:

«En la villa de Santillana Ayuntamiento de este nombre, partido judicial de Torrelavega, en la provincia de Santander, a 
treinta de septiembre de mil ochocientos ochenta y nueve, reunidos en la Casa Consistorial la Comisión nombrada por la Corporación para realizar el deslinde general del término municipal en cumplimiento de lo prevenido por el Real Decreto de treinta de agosto de mil ochocientos ochenta y nueve... Enseguida el señor Presidente dispuso que se pusiese en marcha la Comisión, y así se verificó en dirección a la Sierra llamada de la Gallina, que es donde se halla el primer mojón divisorio con el Ayuntamiento de Reocín... Mojón numerado 1..$^{\circ}$ Se reconoció como tal el situado en dicho sitio de Sierra de la Gallina que limita al sur con terrenos comunes del pueblo de Ganzo correspondientes al Ayuntamiento de Torrelavega, al Poniente con más del pueblo de Puente San Miguel, perteneciente al de Reocín, y al Saliente con más del pueblo de Mijares de este distrito..."

Operaciones éstas de 1889 realizadas en cumplimiento del Real Decreto de 30 de agosto de 1889 , ordenando la renovación de los hitos o mojones permanentes que determinan las líneas divisorias de los términos municipales. Y que como sucediera en 1925 no eran sino «reconocimientos" o "revisiones" como dice el primer acta, de deslindes ya existentes con anterioridad al año 1889 (aunque no consta en el expediente la existencia de un tercer deslinde entre Torrelavega y Reocín en el año 1889, la lectura del Acta de 1926 no deja lugar a la duda sobre este extremo, pues como sucedió en 1925, el 8 de julio de 1926 también se "reconoció", como hemos visto, la línea de término existente desde antiguo entre ambos municipios).

En conclusión, las líneas de término de los tres Ayuntamientos venian siendo pacíficamente aceptadas desde tiempos inmemoriales: no sólo en 1925, también en 1889 y aún en fechas anteriores, puesto que siempre se procedió al "reconocimiento" de los deslindes existentes.

\section{B) La finalidad estadística y catastral de las operaciones practicadas}

Las operaciones de reconocimiento de los años 1925 y 1926, por otra parte, como se desprende de la transcripción de las actas, se efectúan "para dar cumplimiento a lo que dispone la ley para la publicación del Mapa de treinta de septiembre de mil ochocientos setenta y la de veintitrés de marzo de mil novecientos seis, sobre formación del Catastro parcelario de España". Asoman pues la finalidad fiscal y estadística antes avanzadas en su práctica. 


\section{C) Su carácter de "mutuo acuerdo»}

En fin, importa subrayar en este momento que las tres operaciones practicadas, el 18 de junio de 1925 (entre Santillana del Mar y Torrelavega), el 19 de junio de 1925 (entre Santillana del Mar y Reocín), y el 8 de julio de 1926 (entre Torrelavega y Reocín) fueron deslindes «de mutuo acuerdo" o deslindes "practicados de conformidad" por los Ayuntamientos respectivos, sin que hubira discrepancia alguna sobre el mojón común a los tres términos municipales, reconocido pacíficamente por todos ellos.

\section{La validez de los deslindes practicados en 1925-1926}

A) Determinación de la normativa que rigió la práctica de los deslindes de 1925-1926

El Reglamento sobre Población y Términos Municipales, de 2 de julio de 1924, aprobado apenas un año antes de practicarse los deslindes, se hallaba vigente en el momento en que se practicaron dichas operaciones; rigiéndose además por el Decreto, de 23 de diciembre de 1870, cuyas instrucciones son incorporadas por aquel en su art. 27. Normas éstas mismas, a las que, por otra parte, también se remitía la Ley de 23 de marzo de 1906, sobre el Catastro Parcelario, como se ha visto más arriba, pues no hay que olvidar que el reconocimiento que se practica en estos años tenía una finalidad fundamentalmente catastral.

\section{B) Validez de los deslindes}

Los deslindes fueron ejecutados con plena sujeción a lo dispuesto en el art. 27 del Reglamento sobre Población y Términos municipales, de 2 de julio de 1924: fueron las comisiones de los tres Ayuntamientos, en tres operaciones de deslindes diferentes, las que verificaron los respectivos deslindes de las líneas de término municipal. Sin que, como registrara la carátula de las mismas, hubiera "ninguna incidencia», así como «ningún mojón no reconocido»: un deslinde de "mutuo acuerdo». Y que, en definitiva, suponía el reconocimiento de las líneas de término ya verificadas en 1889 y que venían siendo pacíficamente admitidas, incluso con anterioridad a esa fecha. 


\section{INVALIDEZ E INEFICACIA DE LAS OPERACIONES DEL AÑO 1951}

\section{Las dos operaciones de reconocimiento de la línea de término y señalamiento de mojones comunes de 1951}

En el año 1951, de nuevo se procedió al reconocimiento de las líneas de término y señalamiento de mojones comunes. Si bien se llevaron a cabo solamente dos: los de las lindes de Santillana del Mar y Torrelavega y las de Santillana del Mar y Reocín, pero no se hizo lo propio con las de Reocín y Torrelavega que no fueron objeto de revisión alguna. Y por primera vez afloran divergencias entre los municipios; que se contraen al señalamiento del mojón común a los tres términos municipales, el M3T, hasta ahora indiscutido.

\section{A) Entre Santillana del Mary Reocín, el 9 de junio de 1951}

El Acta de la operación practicada para reconocer la línea de término y señalar los mojones comunes a los términos de Santillana del Mar y Reocín, de 9 de junio de 1951, dice así: «Reunidos el día nueve de junio de mil novecientos cincuenta y uno en el sitio denominado La Garita los señores que con sus respectivos cargos y representación abajo se expresan, previa citación hecha por el Ingeniero Jefe de la brigada topográfica de deslindes, para dar cumplimiento a lo que dispone la ley, para la publicación del Mapa, de treinta de septiembre de mil ochocientos setenta y la de veintitrés de marzo de mil novecientos seis, sobre formación del Catastro parcelario de España..., se procedió a la operación de la forma siguiente...

Vigésimo sexto y último mojón: No existiendo conformidad entre las Comisiones de los Ayuntamientos que asisten a esta operación, respecto a la situación de este mojón que debía ser común a los términos municipales de Santillana del Mar, en su anejo de Mijares, de Reocín, en su anejo de Puente San Miguel y de Torrelavega en su anejo de Ganzo, pertenecientes todos a la provincia de Santander, ni en cuanto a la posesión de derecho, ni a la de hecho, se deja sin describir y en su día se fijará por el Instituto Geográfico y Catastral un punto en el terreno a los sólos efectos de los cierres planimétricos de los términos municipales que al mismo deben concurrir, sin que el citado punto prejuzgue nada en relación con las reclamaciones que tengan presentadas o traten de presentar los Ayuntamientos interesados. Como consecuencia de lo anteriormente expuesto tampoco hubo conformidad entre los 
DICTAMEN EMITDO A REQUERIMIENTO DEL AYUNTAMIENTO DE SANTULANA DEL MAR

Ayuntamientos interesados respecto de la línea de término entre este mojón y el vigésimo quinto que se deja sin describir, no habiéndose aceptado ninguna de las soluciones propuestas por el Topógrafo que suscribe».

Mojón n. ${ }^{\circ} 26$ que era el $n .^{\circ} 12$ en el reconocimiento practicado el 19 de junio de 1925.

B) Entre Santillana del Mar y Torrelavega, el 11 de junio de 1951

Otro tanto pasó dos días después, cuando las respectivas comisiones de Santillana del Mar y Torrelavega no reconocen como mojón común de su línea de término el $n .^{\circ} 1$, común a los tres municipios (y que resultara ser también mojón $n .^{\circ} 1$ en el deslinde de 18 de junio de 1925). El Acta de la operación practicada para reconocer la línea de término y señalar los mojones comunes a los términos de Santillana del Mar y Torrelavega, de 11 de junio de 1951, tiene idéntico tenor al acta inmediatamente transcrita por lo que se omite su transcripción (que puede verse, no obstante, en el punto $4 .^{\circ}$ de los antecedentes), versando el desacuerdo sobre dicho M3T.

Como complemento de estas operaciones, los días 26 de junio y 21 de julio de 1951, los Ayuntamientos en litigio suscribieron sendas Actas adicionales a las redactadas en 1925 , sobre cuyo contenido se habrá de volver en breve.

\section{Alcance, naturaleza y carácter de las operaciones practicadas en 1951}

A) El carácter "controvertido" del deslinde. La indefinición de las líneas de término como consecuencia del desacuerdo

En 1951, por vez primera, las operaciones de deslinde intentadas por las comisiones municipales resultan ser "controvertidas", al no alcanzarse acuerdos entre los municipios de Santillana del Mar y Reocín y Santillana del Mar y Torrelavega (no así entre Torrelavega y Reocín, que ni siquiera llegan a practicarse). El resultado del desacuerdo, como se comprueba por la transcripción de las actas, trajo consigo a la postre una indefinición de las líneas de término afectantes al M3T, el mojón discutido, que «se deja sin describir y en su día se fijará por el Instituto Geográfico y Catastral». 


\section{B) La finalidad estadística y catastral de las operaciones}

Las operaciones del año 1951 perseguían la misma finalidad que las practicadas en los años 1925 y 1926; pudiéndose leer en la parte mecanografiada correspondiente al modelo de actas empleadas, que las mismas se verificaron "para dar cumplimiento a lo que dispone la ley, para la publicación del Mapa, de treinta de septiembre de mil ochocientos setenta y la de veintitrés de marzo de mil novecientos seis, sobre formación del Catastro parcelario de España». Exactamente la misma leyenda que aparecía en las de los años 1925 y 1926.

\section{Invalidez de los deslindes del año 1951}

A) Determinación de la normativa aplicable a los deslindes del año 1951

1. La vigencia del Reglamento sobre Población y Términos Municipales de 1924. Su aplicación

El Real Decreto, Presidencia del Directorio Militar, de 2 de julio de 1924, por el que se aprueba el Reglamento sobre Población y Términos Municipales, gozaba de vigencia en el momento en que se practicaron las operaciones del año 1951. Revisada en la República la obra normativa de la Dictadura de Primo de Rivera por el Decreto, 16 de junio 1931, sobre revisión y clasificación de las disposiciones emanadas durante la Dictadura desde 1923 a 1931, permanece vigente el Reglamento sobre Población y Términos Municipales de 2 julio 1924, merced a su inclusión expresa entre las normas que según el art. $3 .^{\circ}$ de aquel Decreto, se «estiman reducidos al rango de preceptos meramente reglamentarios, válidos si se confirman con el texto de leyes votadas en Cortes».

El Reglamento resistió los embates de las posteriores leyes de régimen local, hasta la sustitución por su homónimo de 17 de mayo de 1952: de la republicana Ley municipal de 31 de octubre de 1935 y de la franquista Ley de Administración Local, de 16 de diciembre de 1950 (en términos que no alterará el Texto Articulado y Refundido, de Régimen Local, de 24 de junio de 1955). Sólo, el Decreto de 17 de mayo de 1952, que aprueba el Reglamento de Población y Demarcación Territorial de las Entidades Locales acaba con la vigencia del viejo Reglamento de 2 de julio de 1924, al que sustituye; y cuyos arts. 26 a 33, incluidos en una sección común que lleva por título «del procedimiento para el deslinde», incorporan, con algún añadido, prácticamente el mismo régimen. 
DICTAMEN EMITIDO A REQUERIMIENTO DEL AYUNTAMIENTO DE SANTILLANA DEL MAR

2. La normativa catastral. El Decreto-Ley de 3 de abril de 1925, sobre formación del Catastro Parcelario Jurídico y el de 30 de mayo de 1928 aprobado para el cumplimiento del anterior

Como quiera que las operaciones de deslinde efectuadas en 1951 lo fueron con una finalidad preferentemente catastral (también estadística) es preciso dar cuenta de las novedades legislativas en esta materia, que por las fechas no resultaron aplicables a los deslindes de 19251926.

Aprobado en 1924 el Reglamento sobre Población y Términos Municipales, al año siguiente se dicta un Real Decreto-Ley, de 3 de abril de 1925, sobre formación del Catastro Parcelario Jurídico de España. Otra vez, y como una pieza previa del Catastro, es necesario tener perfectamente acotados los términos municipales, por lo que el art. 6 del mismo ordena deslindar y amojonar aquéllos que aún no lo estén en el plazo de seis meses. Atendiéndose para la colocación provisional de los hitos o mojones «solamente a la posesión de hecho en el momento en que se lleve a cabo la operación, conforme a lo previsto en las leyes 23 diciembre 1870, 27 marzo 1900, 23 marzo 1906 y R.D. 2 julio 1924, cuando no se pudiera marcar la línea de derecho por haber discrepancia entre los municipios colindantes»; "marcándose una línea provisional que no prejuzgue los derechos que puedan corresponder a cada Ayuntamiento, la cual se respetará hasta que, cumplimentando lo que disponen los arts. 28 y 29 del Real Decreto antes mencionado se pueda proceder a efectuar los amojonamientos administrativos».

De nuevo la legislación sobre el Catastro, como ya sucediera con la Ley de 27 de marzo de 1900, sobre formación del Catastro y la de 23 de marzo de 1906, estableciendo el Catastro Parcelario, ordena la práctica de deslindes en los términos municipales, y de nuevo también se apoya en la norma de la legislación local que por excelencia regula los deslindes, recién aprobada el año anterior, el Reglamento de 1924, cuyo contenido viene a absorber, como acabamos de ver.

El Decreto-Ley de 1925 aún será desarrollado por otra norma, el Real Decreto-Ley, de 30 de mayo de 1928, aprobando el Reglamento para el cumplimiento de los de 3 de abril de 1925 sobre Catastro parcelario jurídico y 6 de abril de 1926 de reorganización de los servicios del Catastro. Una norma que como la de 1925 remite explícita y directamente al Reglamento de Población y Términos Municipales de 1924, completando sus disposiciones. 
En efecto, el art. 11 del Decreto-Ley de 1928, expresamente envía al art. 27 de aquél al efecto de nombrar las comisiones municipales que habían de intentar el deslinde de mutuo acuerdo, reproduciendo además su contenido.

Sus arts. 24 a 26 claramente prescribían el procedimiento subsiguiente al desacuerdo en la práctica del deslinde ("controvertido") que figuraba en los arts. 28 y 29 del Reglamento de 1924. "Cuando por haber discrepancia entre los Municipios colindantes no se pudiera marcar la línea de derecho, se fijará una provisional para su señalamiento se atenderá sólo a la posesión de hecho en el momento en que se lleve a cabo la operación. Esta línea provisional no prejuzgará los derechos que puedan corresponder a cada Municipio, y se expresará en el acta que están conformes con ella, en concepto únicamente de la posesión de hecho y sin perjuicio de las reclamaciones que tengan presentadas, o traten de presentar a la Autoridad competente», decía el primero. $Y$ si las respectivas comisiones no llegasen a ponerse de acuerdo, ni siquiera en la posesión de hecho, ordenaba el art. 25 levantar acta de ella estableciendo cada comisión señales en la línea que el respectivo Ayuntamiento mantenga...

El art. 26, diseñaba la misma solución a los expedientes de deslindes controvertidos que el Reglamento de 1924, la atribución al Ministerio de la Gobernación de la competencia para su resolución, previo informe del Instituto Geográfico y Catastral:

«En los casos señalados en los artículos 24 y 25 las Alcaldías respectivas remitirán las actas, con los demás antecedentes, al Gobernador Civil, quien enviará el expediente a la Dirección general del Instituto Geográfico y Catastral para que, en el plazo de un año, designe este Centro al Ingeniero o Ingenieros que hayan de constituirse sobre el terreno a fin de determinar, en vista y de conformidad con los documentos indicados, el deslinde de los términos municipales de referencia. El Ministro de la Gobernación resolverá el expediente, previo informe del Instituto. Contra su resolución podrá interponerse recurso contencioso-administrativo".

El Decreto-Ley de 1928 fue una norma que aunque las Actas no citan expresamente (quizá porque las mismas se redactan con arreglo a un modelo, que es además idéntico al que presentan las Actas de 1925-1926), y sí en cambio la Ley de 1906, fue clarísimamente objeto de aplicación por el Ingeniero del Instituto Geográfico. Es así como 
se explica que tanto el mojón discutido como las líneas de término se dejaran sin describir, al no haber acuerdo ni sobre la posesión de hecho ni de derecho, en espera de que el Instituto Geográfico y Catastral procediera a una próxima fijación. Pero sobre ello volveremos a continuación, no sin antes advertir que ambas normas se hallaban vigentes en el año 1951; el 6 de agosto de 1932 una nueva Ley catastral derogaba el Real-Decreto Ley de 1925 y su normativa de desarrollo exceptuando de la derogación precisamente al art. 6 , la norma reguladora de los deslindes, declarando en vigor entre otras la Ley de 23 de marzo de 1906.

En conclusión, el Reglamento sobre Población y Términos Municipales, de 2 de julio 1924, se encontraba vigente, y era aplicable, en el momento en que se practican no sólo los deslindes de 1925-1926, sino también los deslindes de 1951. Al tiempo que eran aplicables, dada la finalidad catastral reconocida en las actas de los deslindes, las disposiciones sobre el Catastro Parcelario: la Ley de 23 de marzo de 1906 y los Decretos-Leyes de 3 de abril de 1925, sobre formación del Catastro Parcelario Jurídico de España, y de 30 de mayo de 1928, aprobado en cumplimiento, entre otras normas, del anterior.

B) Para el Derecho no existen actos, válidos y perfectos, de deslinde, en 1951, porque los expedientes nunca llegaron a concluirse

1. $\mathrm{Al}$ resultar «controvertidos» los deslindes era preceptiva una resolución del Ministerio de Gobernación que pusiera fin a los mismos; lo que nunca se produjo

Lógicamente, al no existir acuerdo entre las comisiones de los Ayuntamientos que participaron en ambas operaciones de deslinde, y resultar por tanto "controvertidos», se abría una segunda fase en la que la resolución de los expedientes se atribuía al Ministerio de la Gobernación. Y en la que era preceptiva la intervención del Instituto Geográfico; de ahí el inciso que atribuía a éste la fijación "en su día» del mojón discutido y el cierre de la línea de término. La atribución al Ministerio de la Gobernación de la resolución final del expediente, que era indubitada en el art. 29 del Reglamento sobre Población y Términos Municipales, de 2 de julio de 1924, y en el art. 26 del Real Decreto-Ley, de 30 de mayo de 1928, se vio además confirmada por el art. 21 del Decreto de 16 de diciembre de 1950, Texto Articulado de la Ley de Administración Local, vigente en el momento en que se practican las operaciones de deslinde en el año 1951: 
«Las cuestiones que se susciten entre Municipios sobre el deslinde de sus términos municipales serán resueltas por el Ministro de la Gobernación, previo informe del Instituto Geográfico y Catastral y dictamen del Consejo de Estado».

Aunque sea innecesario incorporar más razones; para corroborar que el expediente de deslinde es inconcluso por falta de resolución del Ministerio de Gobernación, basta con confrontar las numerosas decisiones del Tribunal Supremo que deciden recursos contenciosoadministrativos contra Ordenes del Ministerio de Gobernación sobre deslindes controvertidos de términos municipales al amparo del Reglamento de 1924. A mero título de ejemplo: las SSTS 17 diciembre 1930 (Ar. 53), 15 noviembre 1930 (Ar. 3145), 18 mayo 1933 (Ar. 3183), 15 marzo 1941 (Ar. 570), 16 febrero 1946 (Ar. 156), 24 octubre 1947 (Ar. 1124), 15 noviembre 1950 (Ar. 1514), 13 noviembre 1954 (Ar. 2901), etc. Algunas de ellas tan elocuentes como la STS 15 marzo 1941 (Ar. 570): «la resolución del Ministerio de la Gobernación puso término y causó estado en el expediente, por lo que habían de tenerse por ejecutivos, en tanto que no se suspendiesen sus efectos, por acuerdo de esta jurisdicción"; o la STS 16 febrero 1946 (Ar. 156) - que rechaza la alegación de vicios de procedimiento, entre ellos la posible ausencia de la resolución del Ministerio de la Gobernación-: «que, basada la excepción aludida, según aparece del acta de la vista, en no existir Orden del Ministerio de la Gobernación y sí tan sólo de la Dirección General de la Administración Local, ha de fundarse aquélla en no haber causado estado, por no estar apurada la vía gubernativa, al no haberse ejercitado la lazada, fundamento éste, que carece de realidad, ya que, según aparece en autos, en el traslado de la resolución recurrida, dado por el Gobernador Civil... se consigna literalmente "este Ministerio" y, por tanto, la resolución que se transcribe es del Ministerio de la Gobernación... por tanto carece de fundamento la exepción propuesta»; o en fin, la STS 13 noviembre 1954 (Ar. 2901) que rechazó la alegada falta de competencia del Ministerio de la Gobernación para resolver un expediente de deslinde.

En conclusión, los expedientes de deslinde del año 1951 no fueron concluidos porque al resultar controvertidos, era necesaria su resolución por el Ministerio de Gobernación, según el art. 29 del Reglamento sobre Población y Términos Municipales, de 2 de julio de 1924, el art. 26 del Real Decreto-Ley, de 30 de mayo de 1928 y además el art. 21 del Texto Articulado de la Ley de Administración Local, de 16 de diciembre de 1950. Una resolución que nunca se produjo. 
DICTAMEN EMITIDO A REQUERIMIENTO DEL AYUNTAMIENTO DE SANTILLANA DEL MAR

2. Las operaciones de 1951 son meros actos de trámite de un procedimiento inconcluso que, en consecuencia, no pudieron sustituir a los deslindes existentes

Las dos operaciones de reconocimiento practicadas, las de los términos de Santillana del Mar y Torrelavega, el 9 de junio de 1951, y Santillana del Mar y Reocín, el 11 del mismo mes y año, dado el carácter controvertido de los deslindes, únicamente significaron la plasmación de las «divergencias entre los Ayuntamientos respectivos en cuanto a la manera de apreciar el sitio por donde debe pasar la línea divisoria o donde deben colocarse los hitos o mojones", en los términos del art. 28 del Reglamento, de 2 de julio de 1924, sobre Población y Términos Municipales. Meros actos de trámite de un procedimiento administrativo de deslinde inconcluso a tenor de los arts. 29 del citado Reglamento, 26 del Real Decreto-Ley, de 30 de mayo de 1928 y 21 del Texto Articulado de la Ley de Administración Local de 16 de diciembre de 1950.

La consecuencia directa que de ello se alcanza es la imposibilidad jurídica de que los actos de deslinde de 1951, pudieran sustituir a los deslindes válidamente celebrados en 1925: ni el Acta, de 9 de junio de 1951, relativa a la operación practicada para reconocer la línea de término y señalar los mojones comunes a los términos de Santillana del Mar y Reocín, pudo sustituir, al no ser expresiva de un acto perfecto, a la anterior de 19 de junio de 1925; ni el Acta, de 11 de junio de 1951, referente a las operaciones entre Santillana del Mar y Torrelavega, pudo hacer lo propio con la anterior de 18 de junio de 1925. Sólo una resolución del Ministerio de la Gobernación, competente para resolver el expediente dado su carácter controvertido, pudo haber sustituido a los mismos. Y ello no se produjo, porque, como se repite, nunca hubo resolución del expediente.

Un expediente caducado por mor del art. 113 del Reglamento de Procedimiento del Ministerio de la Gobernación, de 31 de enero de 1947, a la sazón vigente, 'y que prescribía la caducidad de aquéllos cuya tramitación excediera de un año desde que se incoara hasta que recayera resolución definitiva.

C) Sobre el contenido: la indefinición resultante de los actos de trámite de los expedientes de deslindes de 1951

Como consecuencia del desacuerdo de los Ayuntamientos intervinientes en los expedientes de deslindes de 1951 respecto del M3T «se 
deja sin describir y en su día se fijará por el Instituto Geográfico y Catastral», las respectivas líneas de término de los municipios de Santillana del Mar y Reocín; de Santillana del Mar y Torrelavega. Indefinición que es el resultado de una "controversia», que debió haber sido solucionada por el Ministerio de la Gobernación previo informe del Instituto Geográfico y Catastral.

Ahora bien, los actos de las operaciones de deslinde, ni siquiera de haber sido válidos, podrían haber tenido semejante contenido. Pues implica reconocer que determinadas porciones de territorio quedaran fuera de toda "jurisdicción» si ninguno de los municipios la asumía, o sujeta a la de dos o más municipios, si todos ellos la reclamaran. Y ambas opciones son ilógicas.

$Y$ es que si, por esencia, un deslinde de términos municipales es una operación tendente a concretar la línea o líneas limítrofes de los territorios municipales que aparecen confusas o controvertidas, proporcionando certeza y seguridad alli donde no existe, ningún sentido tiene que el resultado de su práctica sea exactamente el contrario. Es decir, que fruto del mismo pueda trocarse la existencia de unas líneas de términos prefijadas y aceptadas desde tiempo inmemorial, por otras que habrian de fijarse en el futuro. De esta forma, se introduce inseguridad e incerteza allí donde existía certeza y seguridad, propiciadas por deslindes anteriores incontrovertidos.

Precisamente esta es la idea que subyace en el Reglamento de Población y Demarcación Territorial, de 17 de mayo de 1952 (aunque no aplicable por las fechas), cuyo art. 28 impide una «nueva fijación, salvo casos excepcionales, en que documentalmente se justifiquen errores materiales o vicios de procedimiento en la delimitación anterior", «cuando los Ayuntamientos estén conformes con los límites existentes en la actualidad, cualquiera que sea la fecha de las actas en que hubieran quedado establecidos». Una norma que hoy sigue vigente gracias a su inclusión en los mismos términos en art. 19 del vigente Reglamento de Población.

Exactamente el principio contrario que el Tribunal Superior de Justicia de Cantabria cree que se deduce de la jurisprudencia del TS, pues en su FJ 9 afirma que:

"la premisa necesaria para que los deslindes anteriores se mantengan en el tiempo es que exista acuerdo entre los municipios que procedieron a suscribirlos y que no hayan sido anulados por actas de deslinde posteriores, de igual valor que aquéllas a las 
DICTAMEN EMITIDO A REQUERIMIENTO DEL AYUNTAMIENTO DE SANTILLANA DEL MAR

que se priva de eficacia, sin que la circunstancia de que no se concretase un deslinde alternativo pueda prevalecer frente a la disconformidad expresa y voluntad anulatoria coincidente entre los Ayuntamientos de Santillana del Mar y Reocín...»

Extremo éste que también soslaya el Consejo de Estado en su Dictamen al dar carácter absolutamente preferente a la «anulación» de las actas.

Y con ello entro a analizar este efecto "anulatorio» de los deslindes de 1925 que a juicio de ambas instancias provocaron los deslindes de 1951.

D) Sobre la "anulación" de las Actas de deslinde, de 18 y 19 de junio de 1925, llevadas a cabo por las Actas adicionales a las anteriores, de 26 de junio de 1951 y de 21 de julio de 1945

Para cerrar el examen sobre el alcance de las operaciones de deslinde celebradas en el año 1951, aún queda por explicar cuál sea el valor jurídico de sendas "Actas adicionales" a las de 18 de junio de 1925 , fechada el 26 de junio de 1951, y a las de 19 de junio de 1925 fechada el 21 de julio de 1951. Unas Actas adicionales que se confeccionaron en lógico correlato con las operaciones de deslinde praticadas unos días antes, el 11 y el 26 de junio de 1951. Interesando en este momento realizar su trascripción literal.

1. Las Actas adicionales de 26 de junio de 1951 (complementaria de la de 18 de junio de 1925) y 21 de julio de 1951 (complementaria de la de 19 de junio de 1925)

De acuerdo con el Acta adicional de la operación practicada para reconocer la línea de término y señalar los mojones comunes a los términos municipales de Santillana del Mar y de Torrelavega, de 26 de junio de 1951, el objeto de la misma era proceder a una «modificación del Acta de reconocimiento de la línea de término y señalamiento de mojones comunes a los términos municipales de Santillana del Mar y de Torrelavega como consecuencia del levantamiento de nueva Acta de deslinde entre los mencionados términos municipales...»; lo que se hizo en la forma siguiente:

«En virtud del nuevo levantamiento del acta de deslinde entre los términos municipales de Santillana del Mar y de Torrelavega efectuado por el Instituto Geográfico y Catastral en once de junio de mil novecientos cincuenta y uno. Queda anulada en su totali- 
dad el acta de deslinde levantada entre estos mismo términos municipales en dieciocho de junio de mil novecientos veinticinco de la que esta es una acta adicional.

Concurrieron al acto en representación de Santillana del Mar... representando al Ayuntamiento de Torrelavega... y en representación del Ayuntamiento de Reocín... En prueba de su conformidad firman conmigo la presente acta todos los señores mencionados y se obligan a sellarla los respectivos Ayuntamientos en Santillana del Mar a veintiséis de junio de mil novecientos cincuenta y uno".

Según el Acta adicional de la operación practicada para reconocer la línea de término y señalar los mojones comunes a los términos municipales de Santillana del Mar y de Reocín, pertenecientes ambos a la provincia de Santander, de 21 de julio de 1951, se procedió a la «operación de la modificación del Acta de reconocimiento de la línea de término y señalamiento de mojones comunes a los términos municipales de Santillana del Mar y de Reocín como consecuencia del levantamiento de nueva Acta de deslinde entre los mencionados términos municipales... en la forma siguiente:

«En virtud del nuevo levantamiento del acta de deslinde entre los términos municipales de Santillana del Mar y de Reocín efectuado por el Instituto Geográfico y Catastral en nueve de junio de mil novecientos cincuenta y uno. Queda anulada en su totalidad el acta de deslinde levantada entre estos mismos términos municipales en diecinueve de junio de mil novecientos veinticinco de la que ésta es una acta adicional.

Concurrieron al acto en representación de Santillana del Mar... en representación del Ayuntamiento de Reocín... En prueba de su conformidad firman conmigo la presente acta todos los señores mencionados y se obligan a sellarla los respectivos Ayuntamientos en Santillana del Mar a veintiuno de julio de mil novecientos cincuenta y uno".

2. Para el Consejo de Estado y el Tribunal Superior de Justicia de Cantabria, el coincidente parecer de las tres representaciones municipales en su voluntad de anular las actas de deslinde de 1925 hace decaer la posibilidad de su utilización para la fijación del M3T.

La "anulación» de las Actas de 1925 acometida por ambas Actas adicionales requiere un examen detenido porque es la clave de bóveda de las decisiones del Consejo de Estado y del Tribunal Superior de Justicia de Cantabria. 
DICTAMEN EMITIDO A REQUERIMIENTO DEL AYUNTAMIENTO DE SANTILLANA DEL MAR

A juicio del alto órgano consultivo:

«El acta de deslinde del 26 de junio de 1951, suscrita por los Ayuntamientos de Santillana del Mar, Torrelavega y Reocín, recoge el coincidente parecer de las tres representaciones Municipales y su expresa voluntad de anular en su totalidad el acta de deslinde levantada el 18 de junio de 1925, en la que se señalaba el mojón (el M3T). Si esta acta fue anulada por la concurrente voluntad de los tres indicados Ayuntamientos, decae la propuesta del Ayuntamiento de Santillana del Mar, asumida por el Ayuntamiento de Reocín, de que la fijación del M3T se fije a partir de la información contenida en la aludida acta de $1925 .$. dado que... dicha acta fue anulada por la posterior...»

Y, en idéntico sentido, la sentencia del Tribunal Superior de Justicia de Cantabria; FJ 8:

«Resulta, por tanto, del todo punto imposible, estimar que la indeterminación del M3T, tal y como quedó precisada en dichas actas reveladoras de la falta de acuerdo entre los municipios implicados con respecto a la ubicación que al mismo le otorgaban las Actas de 1925 y 1926, haga recobrar la vigencia de éstas, simplemente por el mero hecho de su indeterminación desde el año 1951, pues la voluntad concorde de los Ayuntamientos en conflicto fue precisamente privar de eficacia a dichos deslindes realizados en los años 1925 y 1926 y así consta claramente en dichas Actas, que contienen la expresión de "anuladas».

A juicio pues de ambas instancias, el coincidente parecer de las tres representaciones en su voluntad de anular las actas de deslinde de 1925 hace decaer la posibilidad de fijación del M3T a partir de los deslindes de 1925. Sin embargo, tengo que disentir de ambas premisas: pues ni las Actas adicionales pudieron «anular» las actas de 1925, ni existió "coincidente parecer» de las tres representaciones sobre la anulación.

3. El pretendido alcance "anulatorio» de las Actas adicionales

A) Su significado y valor jurídico

Unas actas cuyo significado sólo puede comprenderse en el íter cronológico expuesto, a la luz de las recién practicadas los días 9 y 11 de junio de 1951, puesto que las mismas fueron confeccionadas como operación complementaria de éstas. Habiéndose constatado la discon- 
formidad entre los Ayuntamientos de Santillana del Mar y Torrelavega sobre su línea de término el 11 de junio de 1951, y de igual forma entre los de Santillana del Mar y Reocín el 9 de junio de 1951 (discrepancia que tenía por objeto, en ambos casos, al mojón común a los tres términos); controversia, por tanto, que afectaba a las líneas de término entre los respectivos Ayuntamientos señaladas en 1925, era perfectamente lógico que, volviendo los pasos sobre el tiempo, mostraran su disconformidad con lo entonces actuado. Desacuerdo entre los Ayuntamientos que se plasmó en la inserción de sendas actas adicionales a los deslindes de 18 y 19 de junio de 1925 (entre Santillana del Mar y Torrelavega; y entre Santillana del Mar y Reocín), que se tuvieron por «anuladas". Tal anulación no era sino la expresión de la disconformidad de lo actuado en 1925. Ese es su significado y no otro.

Las Actas adicionales practicadas en 1951 tienen exactamente el mismo valor jurídico que las operaciones de deslinde practicadas y reflejadas en las actas 9 y 11 de junio de 1951, meros actos de trámite de sendos expedientes de deslindes de los términos municipales que nunca han llegado a concluirse, por falta de resolución del Ministerio de la Gobernación. Por esta razón, no puede interpretarse literalmente las expresiones contenidas en las citadas Actas Adicionales, pues nunca pudieron tener virtualidad anulatoria por tratarse de actos de trámite de un expediente inconcluso.

Por ello, y con todo respeto hacia el parecer del Consejo de Estado y del Tribunal Superior de Justicia de Cantabria, no creo acertados sus razonamientos coincidentes en dotar de eficacia anulatoria a las Actas adicionales respecto de las Actas de 18 y 19 de junio de 1925 expresivas del acuerdo de fijación de los límites de término entre Santillana del Mar y Torrelavega, y entre Santillana del Mar y Reocín, deducida exclusivamente del tenor de dichas Actas.

B) No se puede "anular" un acto administrativo mediante su sustitución por otro acto administrativo

El deslinde practicado de "mutuo acuerdo" resulta ser un acto administrativo, dogmáticamente calificado como un "acto complejo" (en la terminología empleada por J.A. Garcia TreviJano, Los actos administrativos, Civitas, $1^{\text {a }}$ ed., 1986, pgs. 229 ss.), esto es, "el acto que resulta del concurso de varios entes u órganos", y en el que es característica que "las voluntades tienen un único contenido y una única finalidad, y se funden para formar un acto único". 
DICTAMEN EMITIDO A REQUERIMIENTO DEL AYUNTAMIENTO DE SANTILLANA DEL MAR

Por lo que la «anulación» de un acto administrativo, como es el que acuerda un deslinde de términos municipales, no puede llevarse a cabo por medio de otro acto administrativo, como pretenden el Consejo de Estado y el Tribunal Superior de Justicia de Cantabria. Las Administraciones no pueden destruir sus actos administrativos anteriores con el dictado de otros posteriores de la misma naturaleza y de contenido contrario. Semejante operación no es sino la admisión de una revocación encubierta, realizada fuera del procedimiento legalmente establecido.

Si realmente la voluntad de los Ayuntamientos en contienda fue la de "anular» los deslindes del año 1925, entonces debieron interponer en 1951 sendos recursos contencioso-administrativos contra sus propias decisiones, previa declaración de su lesividad, en los términos que ordenaba el art. 391 del Texto Articulado de la Ley de Régimen Local, de 16 de diciembre de 1950, vigente a la sazón. Cosa que no se hizo.

4. Sobre la conformidad entre los tres Ayuntamientos que participaron en los deslindes de 1951: no hubo "coincidencia» en la voluntad expresa y anulatoria de los tres Ayuntamientos

En 1951 no sólo no pudo haber "anulación» de los deslindes actuados en 1925, sino que además, en contra de lo que expresamente afirman al unísono el Consejo de Estado y el Tribunal Superior de Justicia de Cantabria no existió "coincidente parecer de las tres representaciones municipales» en su expresa voluntad de anular en su totalidad el acta de deslinde levantada el 18 de junio de 1925 (y la del día siguiente).

Y, a tal efecto, conviene recordar previamente que es lo qué realmente se practicó en las operaciones de deslinde de los años 1925 y 1926. En ambos años, se llevaron a cabo, no uno, sino tres deslindes de términos municipales, y los tres practicados de conformidad por los municipios implicados:

- el 18 de junio de 1925, que fijó la línea de término entre los municipios de Santillana del Mar y Torrelavega;

- el 19 de junio de 1925, que trazó la divisoria entre Santillana del Mar y Reocín; Reocín.

- y el 8 de julio de 1926, que hizo lo propio entre Torrelavega y

En el año 1951, se intentó la modificación de sólo dos de las líneas de término, las dos primeras, quedando inalterada la tercera de ellas. 
- El Acta adicional de 26 de junio de 1951, expresiva de la disconformidad de los Ayuntamientos de Santillana del Mar y de Torrelavega con la delimitación de sus términos municipales fijada el 18 de junio de 1925 , pretendió "anular» dicha acta. Pero en la delimitación de término de ambos municipios el tercero, Reocín, no concurre con su voluntad a la formación del acto de deslinde. Su presencia en el acto, como en el año 1925, unicamente obedece al hecho de tener un mojón común con los dos municipios que deslindaban sus términos municipales. Pero no han de confundirse las cosas. El 26 de junio de 1951 se intenta un deslinde entre Santillana del Mar y Torrelavega exclusivamente.

- Y lo mismo acaece unos días más tarde. El Acta adicional de 21 de julio de 1951, pretende hacer lo propio con la delimitación de los términos municipales entre Santillana del Mar y Reocín verificada en las actas de 19 de junio de 1925. Una operación en la que el Ayuntamiento, ahora el de Torrelavega, tampoco concurre a la formación del acto de deslinde, al ser un tercero.

- En cambio, la tercera de las líneas de término, la que unía los muncipios de Reocín y Torrelavega no sufrió variación alguna, permaneciendo la fijada de mutuo acuerdo en el año 1926.

En contra de lo afirmado por el Consejo de Estado, el Acta adicional de 26 de junio de 1951 no recoge el parecer coincidente de las tres representaciones municipales y su expresa voluntad de anular en su totalidad el acta de deslinde levantada el 18 de junio de 1925. No pudo recoger la voluntad de las tres representaciones municipales porque en dicha operación que pretendía fijar la divisoria entre Santillana del Mar y Torrelavega, no era parte el municipio de Reocín. Que, sin embargo, sí que estuvo presente en las operaciones, porque la línea entre los dos municipios anteriores tenía un mojón que era además común al tercero, cuya citación perseguía evidentemente evitar litigios entre municipios limítrofes. Lo único que recoge el Acta es la presencia en dichas operaciones de los tres municipios conformes con lo efectuado. Textualmente: "Concurrieron al acto en representación de Santillana del Mar... representando al Ayuntamiento de Torrelavega... y en representación del Ayuntamiento de Reocín... En prueba de su conformidad firman conmigo la presente acta todos los señores mencionados y se obligan a sellarla los respectivos Ayuntamientos en Santillana del Mar a veintiséis de junio de mil novecientos cincuenta y uno». Pero se repite una vez más, en la delimitación de la línea entre dos municipios, Santillana del Mar y Torrelavega, el tercero, Reocín, no es parte del deslinde. 
En idéntico sentido, aunque con mayor claridad, se puede percibir en el Acta adicional de 21 de julio de 1951, que recoge la disconformidad de los municipios de Santillana del Mar y Reocín con la línea de término que los unía según las actas de 19 de junio de 1925, y que pretendían anular (aspecto éste, por otra parte, inadvertido en el Dictamen del Consejo de Estado). De nuevo, no pudo recogerse la voluntad conforme de los tres municipios porque la operación afectaba a la línea de término sólo entre dos de ellos, los de Santilllana del Mar y Reocín. Torrelavega no era parte del deslinde de estos dos municipios. Es más, y a diferencia del anterior acta adicional, como se comprueba por la trascripción, ¡ni siquiera figura el Ayuntamiento de Torrelavega en la suscripción de dicha Acta Adicional!, pues al acto sólo concurrieron comisiones en representación de Santillana del Mar y de Reocín, pero no de Torrelavega. Es decir, Torrelavega no sólo no prestó, porque no podía, su asentimiento a la delimitación entre Santillana del Mar y Reocín, sino que, además, ni siquiera suscribió las actas, porque no participó en las operaciones de deslinde.

En suma, el Acta adicional de 26 de junio de 1951 recoge el acuerdo intentando la anulación de la línea de término entre los municipios de Santillana del Mar y Torrelavega acordada el 18 de junio de 1925, con presencia en dicho acto del Ayuntamiento de Reocín; y el Acta adicional de 21 de julio de 1951 el acuerdo entre Santillana del Mar y Reocín haciendo lo propio con la línea de término acordada el 19 de junio de 1925, sin siquiera la presencia del Ayuntamiento de Torrelavega. Pero ello no supone recoger el "coincidente parecer de las tres representaciones municipales y su expresa voluntad de anular en su totalidad" las respectivas actas de deslinde.

- En fin, el deslinde de Reocín y Torrelavega, acordado el 8 de julio de 1926, nunca ha sido "anulado". Y es que en 1951, no existió controversia alguna entre estos dos Ayuntamientos respecto de su línea divisoria, por lo que ha seguido surtiendo plenos efectos.

Este extremo, silenciado por la sentencia del Tribunal Superior de Justicia de Cantabria, es soslayado por el Dictamen del Consejo de Estado en los siguientes términos:

«Así como el acta de deslinde de 18 de junio 1925 fue anulada por la de 26 de julio de 1951, no se comprendió explícitamente en la anulación la de 18 de junio (quiere decir, el 8 de julio, la fecha es errada), de 1926, pero es lo cierto que ésta se suscribió tan sólo por los Ayuntamientos de Reocín y Torrelavega, haciéndose cons- 
tar que al levantamiento del acta "no se ha citado al Ayuntamiento de Santillana para el reconocimiento del expresado mojón. Este mojón, añade el acta, «es el mismo que fue reconocido también como común a los tres referidos términos municipales por los Ayuntamientos interesados al verificarse por el Instituto Geográfico el reconocimiento de términos y señalamiento de mojones comunes a los términos municipales de Santillana y de Torrelavega según acta firmada en la «Sierra de la Gallina» el día 18 de junio de 1925, por cuya razón no se ha citado al Ayuntamiento de Santillana para el reconocimiento del expresado mojón".

De nuevo el Consejo de Estado confunde la suscripción de las actas por los Ayuntamientos presentes en las operaciones de deslindes con el consentimiento de los dos municipios que intentan deslindar sus limítrofes términos municipales. El Acta de 8 de julio de 1926 no tiene menor valor, como parece deducirse por el Consejo de Estado, que el Acta de 18 (o la de 19) de junio de 1925 porque estuviera «suscrita» sólo por dos Ayuntamientos. La finalidad de los deslindes reflejadas en dichas actas es exactamente la misma, fijar las líneas de término entre dos municipios. Y lo cierto es que la fijada el 8 de julio de 1926 ha sido siempre consentida por los dos Ayuntamientos implicados: Santillana del Mar y Reocín.

\section{LA ADMINISTRACIÓN AL RESOLVER EXPEDIENTES DE DESLINDES HA DE BASARSE EN PRIMER LUGAR EN LO QUE RESULTA DE «DESLINDES ANTERIORES PRACTICA- DOS DE CONFORMIDAD POR LOS MUNICIPIOS"}

\section{La doctrina del TS sobre la prevalencia de los deslindes con- sentidos o "de mutuo acuerdo"}

La jurisprudencia del TS, desde una vieja sentencia de 23 de octubre de 1902, continuada por otras de 20 de marzo y 15 de noviembre de 1928 , 18 de enero, 6 de mayo y 2 de octubre de 1936 y 4 de junio de 1941, (entre otras muchas recogidas por el Dictamen del Consejo de Estado, de 8 de junio de 1972, Exp. n. ${ }^{\circ}$ 38.096) viene afirmando indiscutidamente, «que la Administración, para resolver los expedientes de deslinde, ha de basarse, en primer lugar, en lo que resulta de deslindes anteriores, practicados de conformidad por los Municipios interesados».

Este mismo principio es también reconocido por el Dictamen del Consejo de Estado y por la sentencia del Tribunal Superior de Justicia de Cantabria. Así dice el primero: 
«En materia de términos municipales hay que estar, en primer lugar, a lo que resulta de deslindes anteriores consentidos por los Ayuntamientos interesados, debiendo partirse del estado de hecho, respecto de la jurisdicción sólo cuando no hay deslinde anteriormente aprobado y consentido que no pierde eficacia, porque los acuerdos firmes no caducan por el transcurso del tiempo (doctrina jurisprudencial recogida en la Sentencia del Tribunal Supremo, Sala $3 .^{2}$, de 8 de abril de 1967)».

\section{Y su aplicación al presente supuesto}

Sin embargo, para ambas decisiones, el principio de la prevalencia de deslindes anteriores consentidos no entra en juego, porque en su opinión tales deslindes consentidos fueron precisamente los "anulados» en 1951.

Como creo haber demostrado en las páginas anteriores, tal aplicación es rigurosamente inexacta. Debiendo estarse a los deslindes de los años 1925-1926, deslindes practicados de "mutuo acuerdo", o "por conformidad de los municipios interesados", y nunca "anulados" para atender a la determinación del M3T.

En relación con la prevalencia de los deslindes anteriores practicados de mutuo acuerdo aún hay dos extremos que deben ser aclarados. Y es que con la aplicación de esta doctrina se evidencian dos graves desaciertos en la actuación del Instituto Geográfico Nacional, respaldada por el Consejo de Estado.

Primero. En el año 1926, según reflejan las Actas fechadas el 8 de julio, se llevó a cabo un deslinde entre los municipios de Torrelavega y Reocín que no fue revisado en el año 1951 (recordemos que en éste se reconocen sólo dos líneas de término, no tres). Un deslinde "consentido" y nunca puesto en entredicho por ambos municipios. Y al que, por tanto ha de estarse, para trazar la línea límite TorrelavegaReocín. Línea límite entre ambos que tiene en común el M3T, reconocido por ambos Ayuntamientos desde 1926. Al alterarse este mojón por otro nuevo se desconoce la existencia de este deslinde "consentido".

Segundo. Por otra parte, el trazado de las nuevas líneas límites obliga a revisar un mojón, el M2T, común a los municipios de Santillana del Mar y Reocín, que nunca fue discutido. Pues en el año 1951, hubo desacuerdo entre ambos sólo respecto del M3T, pero no respecto de este M2T. De nuevo se pretere un mojón que había sido fijado de 
común acuerdo por los municipios desde tiempos remotos. Este extremo es sencillamente eludido por el Tribunal Superior de Justicia de Cantabria y razonado apodícticamente por el Consejo de Estado: "Sin embargo, considera el Consejo de Estado que la fijación de las líneas geométricas determinantes de los términos municipales, en la confluencia discutida han podido justificar que en la operación asumida por el Instituto se fijara el mojón núm. 3 y se alterara el núm. 2. La autoridad técnica del Instituto, su carácter de tercero en la contienda y la función relevante que el Reglamento de Población y Demarcación Territorial de las Entidades Locales le encomienda al Instituto respaldan que se acepte en conjunto su propuesta. Este es el parecer del Consejo de Estado".

\section{LA EXISTENCIA DE ACTOS REVELADORES DEL EJERCICIO DE POTESTADES ADMINISTRATIVAS COMO CRITERIO SUBSIDIARIO A UTILIZAR PARA RESOLVER LOS EXPE- DIENTES DE DESLINDES}

Criterio en el que se apoyan, tanto el Consejo de Estado como el Tribunal Superior de Justicia de Cantabria, para decidir la ubicación del M3T descartada la utilización de la prevalencia de los deslindes anteriores consentidos. Como afirma el primero:

«Dicho esto, a falta de deslindes anteriores eficaces (sic) adquiere relevancia el indagar si, en el terreno en contienda los Ayuntamientos que propugna que pertenece a su ámbito municipal han ejercido actos reveladores de competencia o potestades administrativas».

\section{La formulación del criterio: el ejercicio de potestades admi-} nistrativas. Su utilización subsidiaria

Sólo cuando no existan deslindes anteriores consentidos en que apoyar una solución al trazado de la línea límite discutida, es posible dar entrada a un segundo criterio, consistente en atender a «los actos reveladores de jurisdicción o potestad administrativa en la zona de conflicto", según jurisprudencia unánime del TS, y extractado en estos términos por el Consejo de Estado en su Dictamen, de la STS 10 diciembre 1958.

Como bien señala el Consejo de Estado, la referencia a la jurisdicción es un concepto indebidamente aplicado: pudo tener justificación su uso en tiempos pasados en los que los Ayuntamientos efectivamente 
ejercían "jurisdicción», siendo hoy más adecuado hablar del ejercicio de competencias administrativas, en sintonía además con el Derecho positivo (art. 12.1 Ley 7/1985, de 2 de abril, de Bases de Régimen Local, que define el término municipal como el territorio en el que el Ayuntamiento ejerce sus competencias).

\section{Los actos de disposición sobre bienes no son actos reveladores de potestades administrativas}

En todo caso, lo que importa advertir es que el deslinde de términos municipales versa sobre lindes que aparecen confusas o controvertidas entre municipios; y las consecuencias que de su práctica se siguen son estrictamente jurídico-administrativas, pero nunca de carácter jurídico-privado o civil. Es decir, que a través del deslinde de términos municipales nunca se deciden cuestiones sobre propiedad. Y en el presente asunto, nadie ha discutido la titularidad dominical de la finca enclavada en la zona de litigio.

Un Ayuntamiento puede ser propietario de bienes ubicados en el término municipal de otro u otros municipios, sin que por dicha razón ejerza potestades administrativas sobre los mismos. Las potestades administrativas son ejercidas por aquel municipio donde dichos bienes radican, pero no por el que es propietario si el bien se localiza fuera de su término municipal. Esta distinción es absolutamente clara en la jurisprudencia del TS. Valga la cita de sólo dos de entre muchas decisiones. La STS 19 junio 1935 (Ar. 1384) afirma que no ha de confundirse:

«el concepto de término municipal, que es el territorio a que se extiende la jurisdicción administrativa de un Ayuntamiento, con la propiedad o posesión de tierras, aprovechamientos u otros derechos de orden patrimonial que pueden pertenecerle dentro o fuera de su término, y en los que en este último caso ejercerá la potestad dominical, pero no la jurisdicción, de la que será titular el Ayuntamiento a cuyo término corresponda, y, en consecuencia, tal posesión carece de eficacia cuando se trata de señalar hasta dónde llega su término municipal».

Y la STS 23 junio 1960 (Ar. 2688):

«No debe perderse de vista que los límites de un término municipal señalan una zona de jurisdicción administrativa, no un área 
de propiedad o de derechos reales; y que, por tanto, aunque se demostrase el dominio de una finca por un Ayuntamiento, ello no resolvería a su favor la cuestión sobre el trazado de su término municipal, ya que no hay obstáculo para que, fuera de dicho término, un Ayuntamiento pueda tener propiedades o disfrutar determinados derechos reales».

La consecuencia que de ello se deduce es la impropiedad de calificar como "actos reveladores" del ejercicio de potestades administrativas las disposiciones patrimoniales efectuadas sobre el inmueble ubicado en la zona de conflicto. No se explica así, como el Tribunal Superior de Justicia de Cantabria puede calificar expresamente como «actos reveladores del ejercicio de potestades administrativas» sendos actos de disposición de bienes, cuales son:

- la cesión gratuita de los terrenos necesarios para la construcción del hospital efectuada por el Ayuntamiento de Torrelavega el 9 de noviembre de 1983 a la Tesorería Territorial de la Seguridad Social,

- al igual que el inicio del expediente de cesión de los terrenos contiguos para la ubicación de un Centro de Atención a Minusválidos Psíquicos en el año 1989.

Que lo único que demuestran es la titularidad dominical de la finca por el Ayuntamiento de Torrelavega, pero nunca pudo probar que «estimaba como perteneciente a su término municipal la parcela en la que se iba a ubicar» (FJ 10, a). Error en el que también incurre el Consejo de Estado cuando reputa «acto revelador» la misma disposición de bienes, así como la inclusión en el Padrón de bienes inmuebles de naturaleza rústica de la totalidad de la finca "como propiedad municipal del Ayuntamiento de Torrelavega» (consideración IV, in fine).

\section{La existencia de actos reveladores del ejercicio de potestades administrativas por los tres Ayuntamientos en litigio}

Del expediente se deduce claramente la existencia de actos reveladores del ejercicio de potestades administrativas realizados por los tres municipios, no sólo por el de Torrelavega.

Del mismo modo que el Ayuntamiento de Torrelavega efectuó una modificación de su Plan General de Ordenación Urbana, para cambiar la calificación y uso del suelo (sistema general en suelo no urbanizable, 
DICTAMEN EMITIDO A REQUERIMIENTO DEL AYUNTAMIENTO DE SANTILLANA DEL MAR

de uso deportivo) con la finalidad de posibilitar la instalación de un centro sanitario; los de Reocín y Santillana del Mar acometieron sendas modificaciones de sus Normas subsidiarias con el objeto de calificar el suelo como urbano para uso sanitario-asistencial.

Si el M.O.P.T. (que no el Ayuntamiento de Torrelavega, como afirma la sentencia del Tribunal Superior de Justicia), realizó proyectos de infraestructura para la puesta en funcionamiento del hospital, como los accesos provisionales al hospital, a través del término municipal de Torrelavega (ni siquiera dentro de la zona discutida); la Diputación Regional de Cantabria ha hecho lo propio en los términos municipales de Santillana del Mar y Reocín.

Y todas estas actuaciones reveladoras del ejercicio de potestades administrativas sobre la zona en litigio se han realizado en un lapso de tiempo muy próximo, sin que el mismo sea tan amplio como para justificar el uso que de este criterio hacen tanto el Tribunal Superio de Justicia como el Consejo de Estado. La STS 30 noviembre 1964 (Ar. 5707), por ejemplo reputa lícita la utilización del "precedente de los actos de autoridad y gestión administrativa efectuados durante un largo período de tiempo (¡más de cien años!) sin encontrar una oposición equivalente por parte de la Corporación vecina».

\section{Al contrarrestarse los actos reveladores, el criterio no es apto para su utilización}

Y es que como señalara la STS 31 mayo 1955 (Ar. 1914):

"Que en cuanto a los numerosísimos documentos aportados por ambas partes para acreditar actos jurisdiccionales, la propia Orden Ministerial reconoce su inutilidad a efectos de la controversia, en razón a contrarrestarse mutuamente...»

\section{CONCLUSIONES}

$1 .^{\mathrm{a}} \quad$ En los años 1925 y 1926 se practicaron de mutuo acuerdo tres operaciones de deslinde entre los tres municipios (Santillana del MarTorrlavega, el 18 de junio de 1925; Santillana del Mar-Reocín, el 19 de junio de 1925 y Torrelavega-Reocín, el 8 de julio de 1926), resultando de las mismas el reconocimiento de las líneas de término existentes entre éstos desde tiempos inmemoriales, y al menos, que se tenga noticia 
cierta, desde el año 1889. Deslindes que fueron verificados con plena sujeción a lo dispuesto en el art. 27 del Reglamento sobre Población y Términos Municipales de 2 de julio de 1924, siendo por tanto perfectamente válidos y eficaces.

2. En el año 1951, se verificaron no tres, sino sólo dos operaciones de reconocimiento de las líneas de término (Santillana del Mar-Reocín, el 9 de junio de 1951 y Santillana del Mar-Torrelavega, el 11 de junio de 1951), resultando ambas controvertidas al no llegarse a un acuerdo entre las respectivas comisiones municipales sobre la ubicación del M3T, mojón común a los tres términos municipales. Dichas operaciones son meros actos de trámite de sendos procedimientos de deslinde inconclusos al ser preceptiva una resolución del Ministerio de la Gobernación, por así disponerlo los arts. 29 del Reglamento sobre Población y Términos Municipales de 2 de julio de 1924, el art. 26 del Decreto-Ley, de 30 de mayo de 1928 sobre el Catastro Parcelario Jurídico y el art. 21 del Texto Articulado de la Ley de Administración Local; una resolución que, sin embargo, nunca tuvo lugar. Incluso de haber sido válidos y perfectos los deslindes referidos, nunca pudieron tener semejante contenido (la indefinición de las líneas de término como consecuencia del desacuerdo) por ser dicho resultado contrario al sentido y finalidad que persiguen las operaciones de deslinde: introducir certeza y seguridad allí donde no existe por haber confusión sobre los linderos.

3. Las Actas adicionales de deslinde de 26 de junio de 1951 (complementaria de la de 18 de junio de 1925) y 21 de julio de 1951 (complementaria de la de 19 de junio de 1925) ni pudieron "anular» los deslindes de 1925, ni recogieron el parecer coincidente de las tres representaciones municipales sobre la "anulación". No pudieron "anular» los dos deslindes practicados en 1925 por tener la misma naturaleza que las operaciones practicadas y reflejadas en las Actas de 9 y 11 de junio de 1951 (actos de trámite de un procedimiento inconcluso y caducado por faltar la resolución del Ministerio de la Gobernación) ni porque unos actos administrativos posteriores de contenido contrario pueden "anular" otros anteriores de la misma naturaleza, resultando una revocación encubierta realizada fuera de procedimiento. Las Actas adicionales únicamente eran expresivas de la disconformidad de los Ayuntamientos respecto de lo actuado en el año 1925, ese es todo su valor jurídico. Ni tampoco recogen el parecer coincidente de las tres representaciones municipales: sólo se intentaron practicar dos deslindes bilaterales (que no un único deslinde "a tres bandas») entre los Ayuntamientos de Santillana del Mar y Torrelavega y los de Santillana del Mar y Reocín. 
DICTAMEN EMITIDO A REQUERIMIENTO DEL AYUNTAMIENTO DE SANTILLANA DEL MAR

4. ${ }^{\text {a }}$ Según una reiterada y unánime doctrina jurisprudencial, la Administración al resolver expedientes de deslinde ha de basarse en primer lugar en lo que resulte de deslindes anteriores "practicados de conformidad por los municipios» o "consentidos». Este criterio obliga a fijar el M3T en el sitio exacto en que fue "reconocido" por los deslindes de los años 1925-1926, respetando una delimitación que había venido surtiendo efectos desde la antigüedad hasta el día de hoy.

5. $\quad$ El criterio para la resolución de expedientes de deslindes que atiende a la existencia de actos reveladores del ejercicio de potestades administrativas no puede entrar en juego en este supuesto, habida cuenta su carácter subsidiario; también proclamado por una doctrina asentada del Tribunal Supremo y del Consejo de Estado, dado que existen deslindes consentidos anteriores a los que es preciso atender. Sin que, además, pudiera nunca dicho criterio llegar a aplicarse en los términos en que lo ha sido (atendiendo exclusivamente a las actuaciones del Ayuntamiento de Torrelavega), toda vez que existen, en un período de tiempo próximo, actos reveladores del ejercicio de potestades administrativas de los tres Ayuntamientos en litigio, que resultan por ello contrarrestados; deviniendo en inútil dicho criterio.

Tal es mi dictamen que someto a cualquier opinión mejor fundada en Derecho.

Santander, a 1 de julio de 1995. 


\section{Sección Jurisprudencia}

REALA-1995, núm. 265. CALVO SANCHEZ, LUIS. DICTAMEN EMITIDO A REQUERIMIENTO DEL ... 
